\title{
The Organization of Dorsal Frontal Cortex in Humans and Macaques
}

\author{
Jérôme Sallet, ${ }^{1}$ Rogier B. Mars, ${ }^{1,2}$ MaryAnn P. Noonan, ${ }^{1}$ Franz-Xaver Neubert, ${ }^{1}$ Saad Jbabdi, ${ }^{2}$ Jill X. 0'Reilly, ${ }^{2}$ \\ Nicola Filippini, ${ }^{2,3}$ Adam G. Thomas, ${ }^{2,4}$ and Matthew F. Rushworth ${ }^{1,2}$ \\ ${ }^{1}$ Department of Experimental Psychology, University of Oxford, Oxford OX1 3UD, United Kingdom, ${ }^{2}$ Centre for Functional Magnetic Resonance Imaging of \\ the Brain, University of Oxford, John Radcliffe Hospital, Oxford OX3 9DU, United Kingdom, ${ }^{3}$ Department of Psychiatry, Warneford Hospital, University of \\ Oxford, Oxford OX3 7JX, United Kingdom, and ${ }^{4}$ Functional MRI Facility, National Institute of Mental Health, National Institutes of Health, Bethesda, \\ Maryland 20892
}

The human dorsal frontal cortex has been associated with the most sophisticated aspects of cognition, including those that are thought to be especially refined in humans. Here we used diffusion-weighted magnetic resonance imaging (DW-MRI) and functional MRI (fMRI) in humans and macaques to infer and compare the organization of dorsal frontal cortex in the two species. Using DW-MRI tractographybased parcellation, we identified 10 dorsal frontal regions lying between the human inferior frontal sulcus and cingulate cortex. Patterns of functional coupling between each area and the rest of the brain were then estimated with fMRI and compared with functional coupling patterns in macaques. Areas in human medial frontal cortex, including areas associated with high-level social cognitive processes such as theory of mind, showed a surprising degree of similarity in their functional coupling patterns with the frontal pole, medial prefrontal, and dorsal prefrontal convexity in the macaque. We failed to find evidence for "new" regions in human medial frontal cortex. On the lateral surface, comparison of functional coupling patterns suggested correspondences in anatomical organization distinct from those that are widely assumed. A human region sometimes referred to as lateral frontal pole more closely resembled area 46 , rather than the frontal pole, of the macaque. Overall the pattern of results suggest important similarities in frontal cortex organization in humans and other primates, even in the case of regions thought to carry out uniquely human functions. The patterns of interspecies correspondences are not, however, always those that are widely assumed.

\section{Introduction}

The dorsal frontal cortex (DFC) is associated with high-level control of cognition (Petrides, 2000; Koechlin et al., 2003; Koechlin, 2011; Passingham and Wise, 2012). In many cases, the cognitive processes with which it is concerned are the ones that are especially developed in humans. For instance, human anterior DFC is associated with tracking of the intentions and beliefs of others sometimes referred to as "theory of mind" (Behrens et al., 2008; Frith and Frith, 2012). Both medial and lateral anterior DFC regions are coactive when we engage in complex behavioral interactions with others (Yoshida et al., 2010).

We know little about human prefrontal cortex connections, even though a region's connections constrain and determine its functions. Our knowledge of human prefrontal organization is principally based on inferences from neuroanatomical studies of areas with similar cytoarchitecture in nonhuman primates, usually macaques (Petrides and Pandya, 1994, 1999; Petrides, 2005). Inferences about human brain function from studies conducted

\footnotetext{
Received Oct. 31, 2012; revised March 26, 2013; accepted April 23, 2013.

Author contributions: J.S. and M.F.R. designed research; J.S., R.B.M., M.P.N., N.F., and A.G.T. performed research;

J.S., R.B.M., M.P.N., F.-X.N., S.J., J.X.O., and M.F.R. analyzed data; J.S., R.B.M., and M.F.R. wrote the paper.

This research is supported by the MRC (J.S., R.B.M., M.F.R.)

Correspondence should be addressed to Jérôme Sallet, Department of Experimental Psychology, University of

Oxford, 0xford 0X1 3UD, United Kingdom. E-mail: Jerome.sallet@psy.ox.ac.uk.

DOI:10.1523/JNEUROSCI.5108-12.2013

Copyright $\odot 2013$ the authors $\quad 0270-6474 / 13 / 3312255-20 \$ 15.00 / 0$
}

in macaques, however, may be unwarranted if there are differences in neuroanatomical organization in the two species as sometimes has been suggested (Ramnani et al., 2006).

To compare DFC in humans and macaques we exploited recently developed diffusion-weighted magnetic resonance imaging (DW-MRI) and functional MRI (fMRI) techniques. First, we used DW-MRI tractography-based parcellation (Johansen-Berg et al., 2004) to delineate component regions within human DFC. Tractography was used to estimate connectivity profiles for voxels in MRI scans of DFC, and voxels with similar estimated connectivity profiles were identified. This technique has been used to identify areas in parietal cortex that resemble in distribution, organization, and position the principle areas identified in cytoarchitectonic studies of parietal cortex (Caspers et al., 2006, 2008, 2011; Scheperjans et al., 2008a; Mars et al., 2011). In the present study, we applied similar techniques to the entire DFC; there is limited published information concerning the locations in standard Montreal Neurological Institute $(\mathrm{MNI})$ space of DFC regions.

While diffusion-based tractography can identify many of the principle component areas within regions of cortex on the basis of discontinuities in estimated connectivity profiles of voxels, the connectivity profiles estimated from diffusion become more uncertain with distance (Mars et al., 2012a). By contrast, coupling strength between blood oxygenation level-dependent (BOLD) signals in different regions ("functional coupling") allows us to investigate in which networks an area participates even when 
those areas are distant (Margulies et al., 2009; Mars et al., 2011; Hutchison et al., 2012b). Cross-species comparisons of such coupling signals therefore provide a way of comparing brain networks across species. We examined patterns of BOLD coupling between DFC areas and brain regions known to be homologous in the two species in 36 humans, and compared them with patterns of BOLD coupling between DFC areas and other brain regions in 20 macaques.

\section{Materials and Methods}

Our investigation of human DFC and comparison with macaque DFC consisted of the same three component stages as a previous investigation of parietal cortex (Mars et al., 2011) (Fig. 1a): (1) an initial DW-MRI parcellation of human DFC; (2) an examination of BOLD coupling patterns in humans DFC; and (3) a comparison of these BOLD coupling patterns with those of macaque DFC.

$D W-M R I$ and tractography-based parcellation. Diffusion-weighted images were acquired in nine healthy subjects (four females; age range, $20-36$ years; mean \pm SD age, $26.9 \pm 6.0$ years) on a $1.5 \mathrm{~T}$ Siemens Sonata MR scanner, with maximum gradient strength of $40 \mathrm{mT} /$ $\mathrm{m}^{-1}$. This approximate number of participants has previously been established as sufficient for obtaining reliable parcellation results in studies using DW-MRI (9 subjects, Johansen-Berg et al., 2004; 6 subjects, Anwander et al., 2007; 11 subjects, Beckmann et al., 2009; 11 subjects, Mars et al., 2011) and fMRIbased parcellation (12 subjects, Goulas et al., 2012). These results have proven reliable in subsequent replication studies using the same or similar methods. For example, Caspers et al. (2011) showed results similar to those of Mars et al. (2011), and Klein et al. (2007) replicated the results of Johansen-Berg et al. (2004) and Anwander et al. (2007). Moreover, the reliability of these types of approaches has previously been demonstrated empirically. Tomassini et al. (2007) demonstrated the replicability of cluster borders across participants. Zhang et al. (2012) showed identical parcellation results independent of whether the parcellation was performed in 21 or 10 participants. Klein et al. (2007) demonstrated the reliability of DWMRI-based parcellations across subjects, scanners, and analysis methods. All participants gave informed written consent in accordance with ethical approval from the local ethics committee. Participants lay supine in the scanner, and cushions were used to reduce head motion. Diffusionweighted data were acquired using echoplanar imaging (EPI; 72- $\times 2-\mathrm{mm}-$ thick axial slices; matrix size, $128 \times 104$; field of view, $256 \times 208 \mathrm{~mm}$; voxel size, $2 \times 2 \times 2 \mathrm{~mm}$ ). Diffusion weighting was isotropically distributed along 60 directions using a $B$ value of $1000 \mathrm{~s} / \mathrm{mm}^{-2}$. For each set of diffusionweighted data, five volumes with no diffusion weighting were acquired throughout the acquisition. Three sets of diffusion-weighted data were acquired for subsequent averaging to improve the signal-to-noise ratio. The total scan time for the diffusion-weighted imaging protocol was $45 \mathrm{~min}$. A structural scan was acquired for each participant in the same session, using a T1-weighted 3D FLASH sequence [repetition time $(\mathrm{TR})=12 \mathrm{~ms}$; echo time

\section{b Dorsal prefrontal cortex mask ( $\mathrm{n}=9$ subjects)}
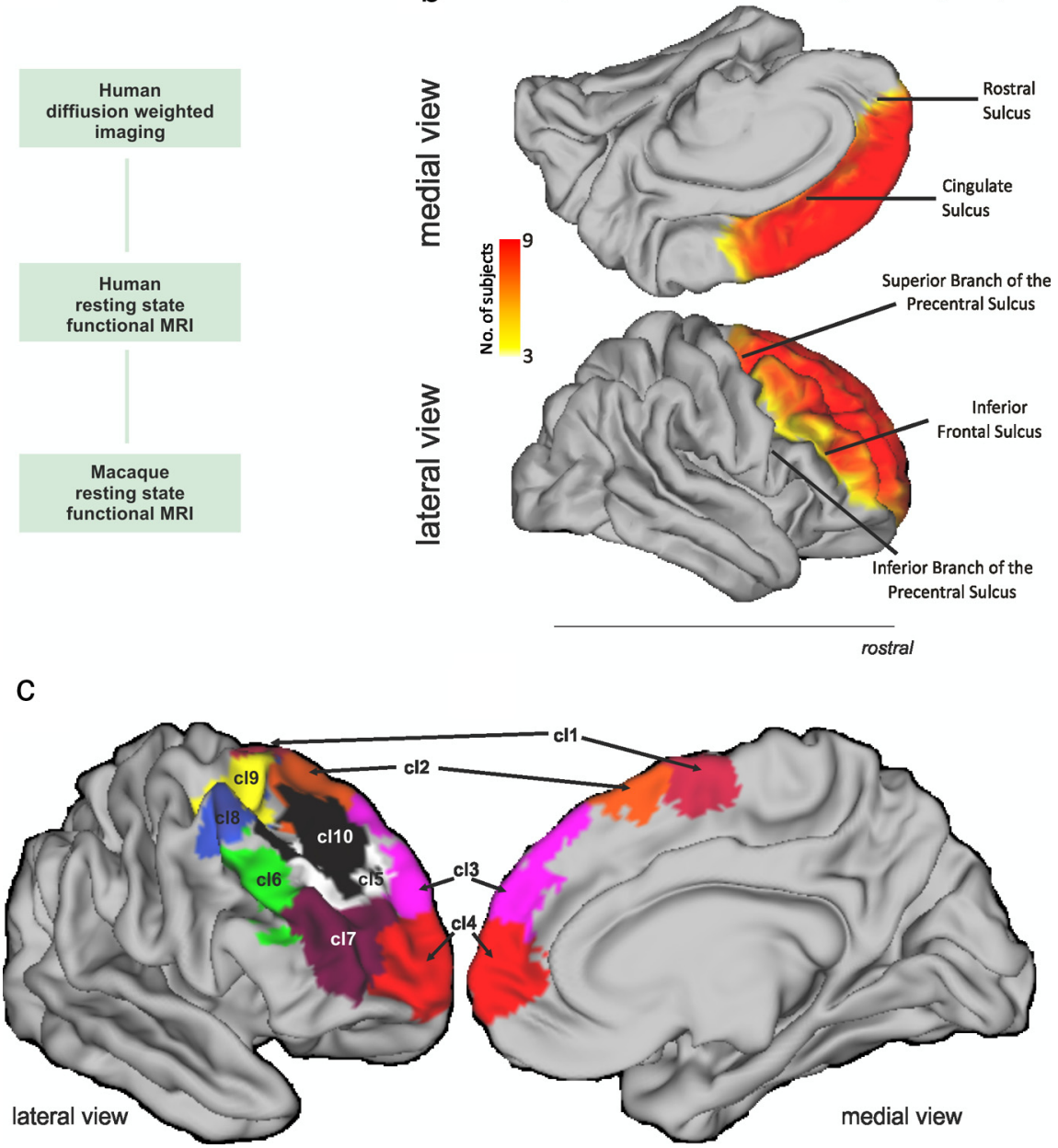

Figure 1. a, The investigation consisted of three parts. First, we used DW-MRI tractography to parcellate human DFC. This approach has previously been shown to identify many of the key cytoarchitectonic regions when applied to other brain areas. Second, we examined resting-state BOLD coupling patterns between the dorsal frontal clusters we had found in the first step and regions in other parts of the human brain. Finally, we examined resting-state BOLD coupling patterns between dorsal frontal regions in the macaque. We examined BOLD coupling patterns because, in comparison with DW-MRI tractography, they are less participate in both humans and macaques. The networks associated with different frontal areas can then be compared and the resting-state functional coupling patterns in the macaque can be compared with the known anatomical connections in the same species. $\boldsymbol{b}$, The dorsal frontal region investigated extended from the inferior frontal sulcus on the lateral surface to the cingulate sulcus on the medial surface. Rostrally, it included the frontal pole, and caudally it extended to the superior precentral sulcus or to a similar position on the medial surface. The region investigated therefore included all the tissue commonly called dorsolateral PFC, dorsomedial PFC, pre-SMA, SMA, FEF, and dorsal parts of the frontal pole and parts of PMd. The degree of overlap in the area investigated in nine subjects after registration to standard MNI space is indicated by the color (scale bar shown at center). $c$,

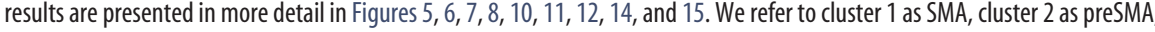
cluster 3 as area 9 , cluster 4 as area 10 , cluster 5 as area $9 / 46 \mathrm{~d}$, cluster 6 as area $9 / 46 \mathrm{v}$, cluster 7 as area 46 , cluster 8 as area $8 \mathrm{~A}$, cluster 9 as the rostral PMd, and cluster 10 as area $8 B$.

$(\mathrm{TE})=5.65 \mathrm{~ms}$; flip angle $=19^{\circ}$; with elliptical sampling of $k$ space, giving a voxel size of $1 \times 1 \times 1 \mathrm{~mm}$.

Analyses and data visualization were performed using tools from FreeSurfer (Athinoula A. Martinos Center for Biomedical Imaging), FSL (Smith al., 2004), and the Connectome Workbench of the Human Connectome Project (http://www.humanconnectome.org/connectome/connectome-workbench. $\mathrm{html})$. A DFC region of interest (ROI) was drawn by hand in each participant's right hemisphere directly on the cortical surface model produced by FreeSurfer (Fig. 1b). In the absence of detailed cytoarchitectonic measurements, it is necessary to use macroscopic boundaries that can be reliably identified in all individuals as the boundaries of the ROI. The fundus of the inferior frontal sulcus formed the ventral and lateral boundary of the ROI. The ventral and medial boundary was drawn following the cingulate sulcus, 


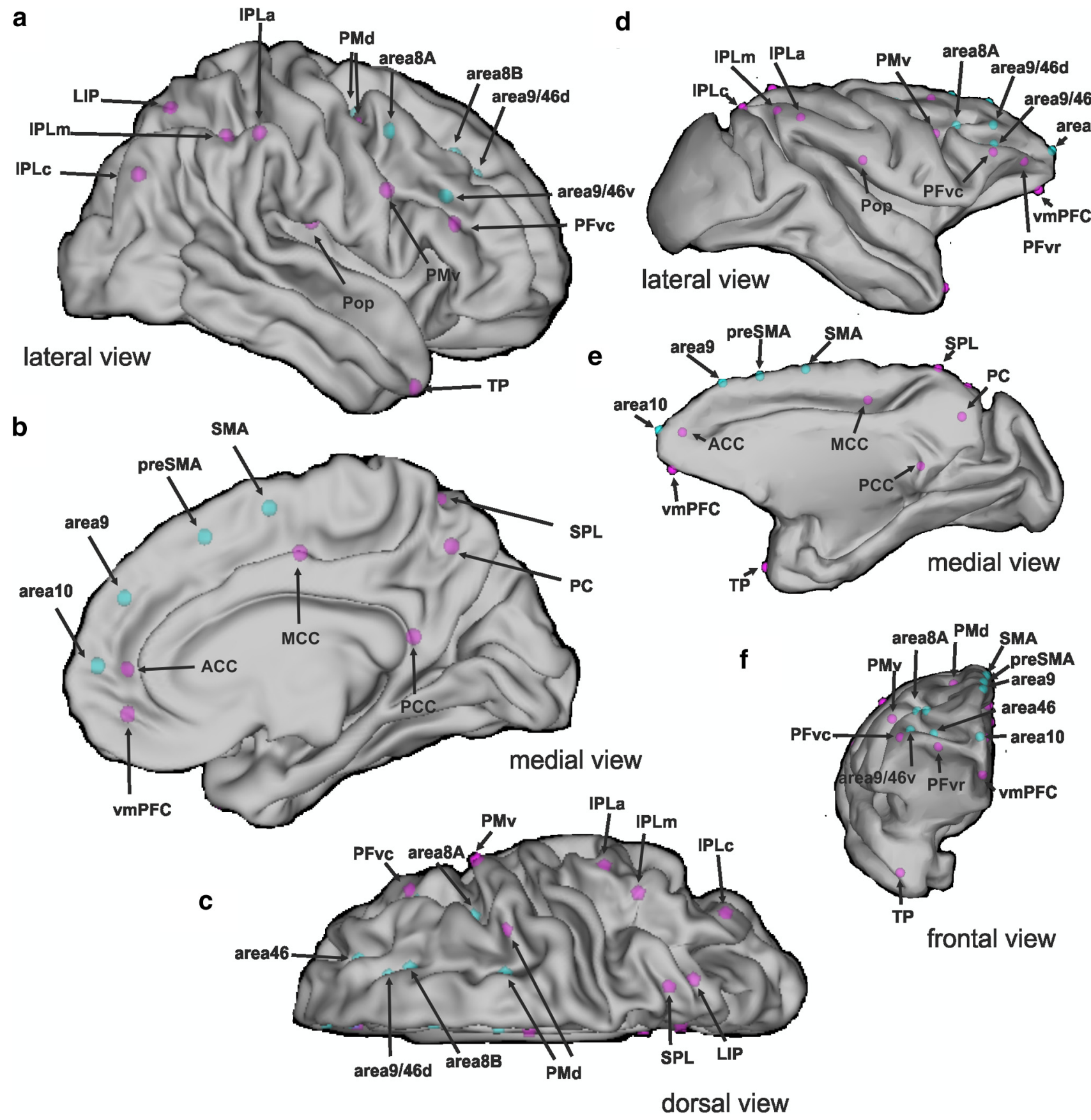

Figure 2. $\boldsymbol{a}-\boldsymbol{f}, \mathrm{ROls}$ in humans $(\boldsymbol{a}-\boldsymbol{c})$ and macaques $(\boldsymbol{d}-\boldsymbol{f})$. The resting-state functional coupling between each DFC regions (blue dots) and each of the target regions (purple dots) was estimated in both humans and macaques to determine how closely DFC networks corresponded in the two species. Note that the size of the dots does not refer to the actual size of the ROls.

and more rostrally the rostral sulcus. The inferior and superior branch of the precentral sulcus formed the caudal and lateral boundary. The superior branch of the precentral sulcus was extended to the medial surface to form the medial and caudal boundary of the ROI. Although there is individual variation in some aspects of the prefrontal cortex's sulcal anatomy, these boundaries identified a similar location in the brains of all subjects after affine registration into MNI space.

The study focuses on the right hemisphere, which is not dominant for language in right-handed humans. There may be hemispheric differences in the human brain, albeit in language areas, but these are mostly outside the region we investigate here. There is little evidence that hemispheric differentiation exists in the macaque (Passingham, 2008).

DWI-MRI data were preprocessed using tools from FDT (part of FSL 4.1). Eddy-current distortions were corrected using affine registration of all volumes to a target volume with no diffusion weighting. Voxelwise estimates of the fiber orientation distribution were calculated using Bedpostx, limited to estimating two fiber orientations at each voxel, because of the $B$ value and the number of gradient orientations in the diffusion data (Tomassini et al., 2007). For each participant, probabilistic tractography was run from vertices at the gray matter/white matter boundary surface within the prefrontal ROI to assess connectivity with every brain voxel (down-sampled to $5 \mathrm{~mm}$ isotropic voxels), using a model accounting for multiple fiber orientations in each voxel (Behrens et al., 2007). Crucially, tractography was seeded from surface vertices (as opposed to voxels). From each seed vertex, the normal to the cortical surface was given by the FreeSurfer cortical model, and this information was used to track toward the brain, instead of tracking in both directions as is usually done in voxel-based tractography. This approach reduces dramatically the risks of creating spurious sample tracts that cross gyral walls (for details, see www.fmrib.ox.ac.uk/fsl/fdt/fdt_surfaces.html). 


\section{a Cluster 1: SMA Dorsal view}
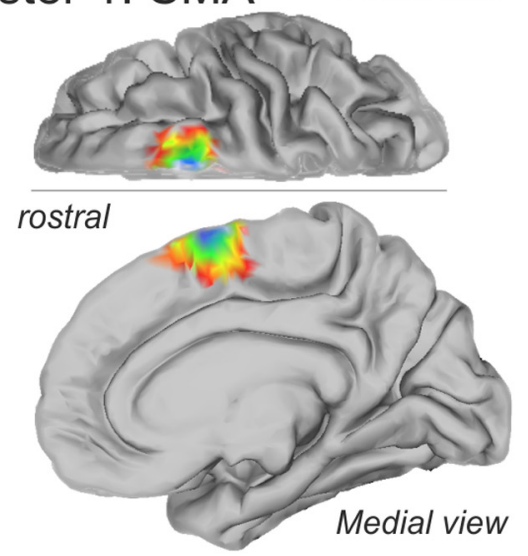

b Cluster 2: PreSMA

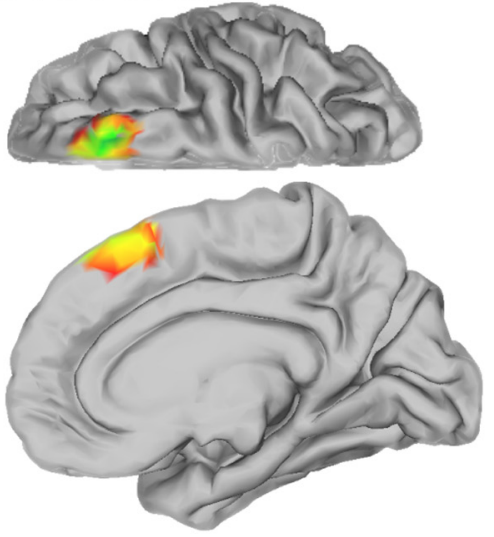

\section{c Cluster 3: Area 9}
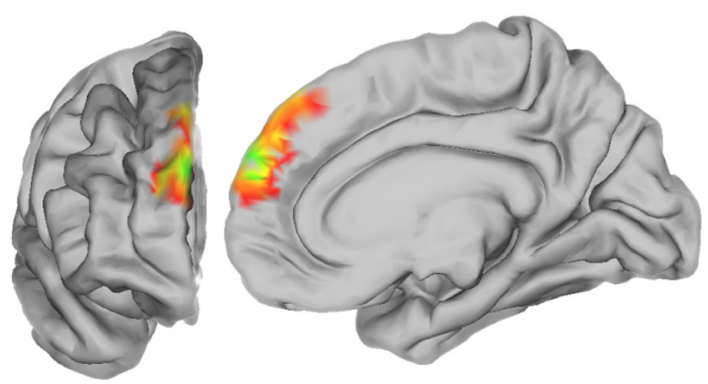

\section{d Cluster 4: Area 10}

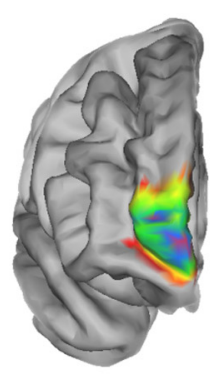

Frontal view

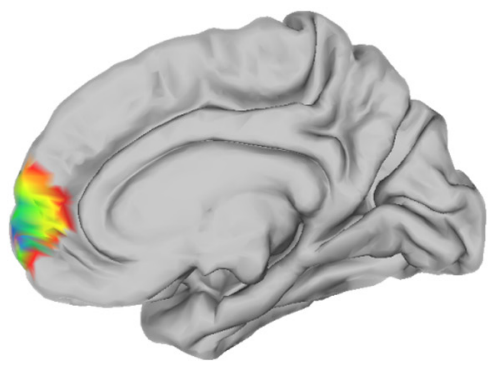

39

$\mathrm{Nb}$ Subjects

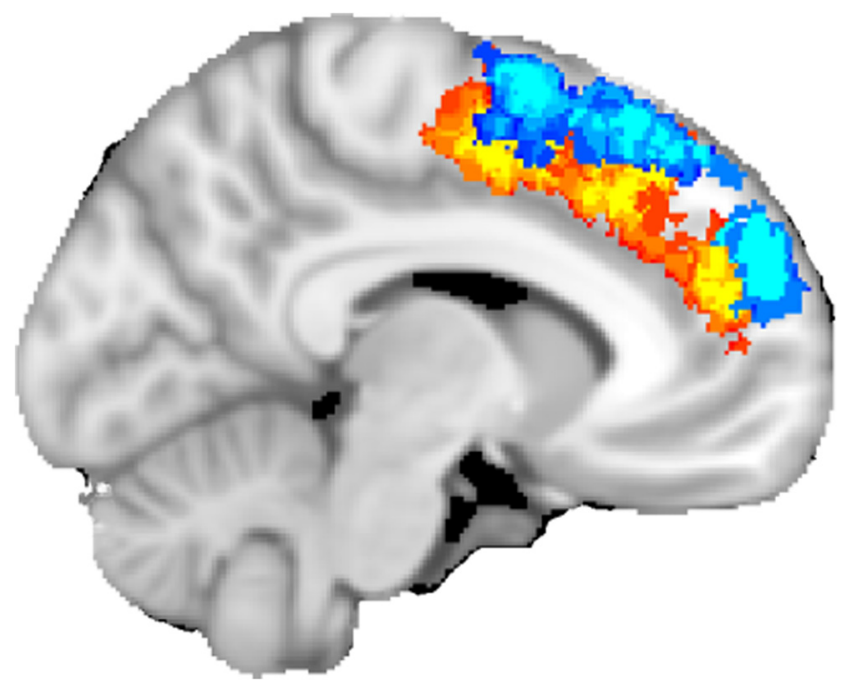

Figure 4. The initial first-pass parcellation of the three more posterior dorsomedial frontal areas, clusters 1, 2, and 3, could be further parcellated each into two areas. In each case, the parcellation resulted in a more dorsal area and a more ventral area. The ventral areas all corresponded to regions of the cingulate cortex that have been previously described (Beckmann et al., 2009) and were not investigated further in the current study. The dorsomedial clusters 1,2, and 3 shown in Figures 5, 6, and 7, together with their associated coupling patterns, correspond to the dorsal tier of areas shown here.

A connectivity matrix between prefrontal vertices and each brain voxel was derived as described previously (Johansen-Berg et al., 2004) and was used to generate a symmetric cross-correlation matrix of dimensions (number of seeds $\times$ number of seeds) in which the $(i, j)$ th element value is the correlation between the connectivity profile of seed $i$ and the connectivity profile of seed $j$. The rows of this cross-correlation matrix were then permuted using $k$-means segmentation for automated clustering to define different clusters. The goal of clustering the cross-correlation matrix is to group together regions that share the same connectivity with the rest of the brain. To increase the chances of obtaining continuous, or nonscattered, clusters, we included a weak connexity constraint (Tomassini et al., 2007). This also ensures that the parcellation of such a large area, which has only been attempted once before in the case of the parietal cortex (and with a similar constraint, Mars et al., 2011), is not simply partly driven by connections between frontal cortical areas themselves. The DFC contains several sulci, notably the superior frontal sulci and the complex intermediate frontal sulcus (Petrides, 2005), and the Euclidean distance between different banks of the same sulcus is small even though the banks are far apart in cortical distance. The flattening of the brain in FreeSurfer space, however, made it possible to implement the connectivity constraint along a geodesic that followed the cortical surface. The resulting clusters were thus constrained to consist of vertices that are spatially contiguous, although the border between clusters is still guided by remote connectivity information.

The number of clusters in the $k$-means clustering must be set by the experimenter. To determine the optimal number of clusters resulting in consistency across participants, we used an iterative procedure (Beckmann et al., 2009; Mars et al., 2011, 2012a). Over the course of several iterations of analysis of each subject's data, we increased the number of clusters that were sought by the $k$-means clustering algorithm until the results returned were no longer consistent across subjects. Intersubject consistency was best with a

$\leftarrow$

Figure 3. Tractography-based parcellation revealed four clusters in human dorsomedial frontal cortex. $\boldsymbol{a}-\boldsymbol{d}$, In each case the clusters' BOLD coupling patterns with other brain regions suggested similarities with particular areas of macaque DFC: cluster 1 resembled SMA (a), cluster 2 resembled pre-SMA (b), cluster 3 resembled area $9(\boldsymbol{c})$, and cluster 4 resembled area 10 (d). Colors indicate the degree of overlap in the cluster placement across subjects (scale bar shown at bottom). 


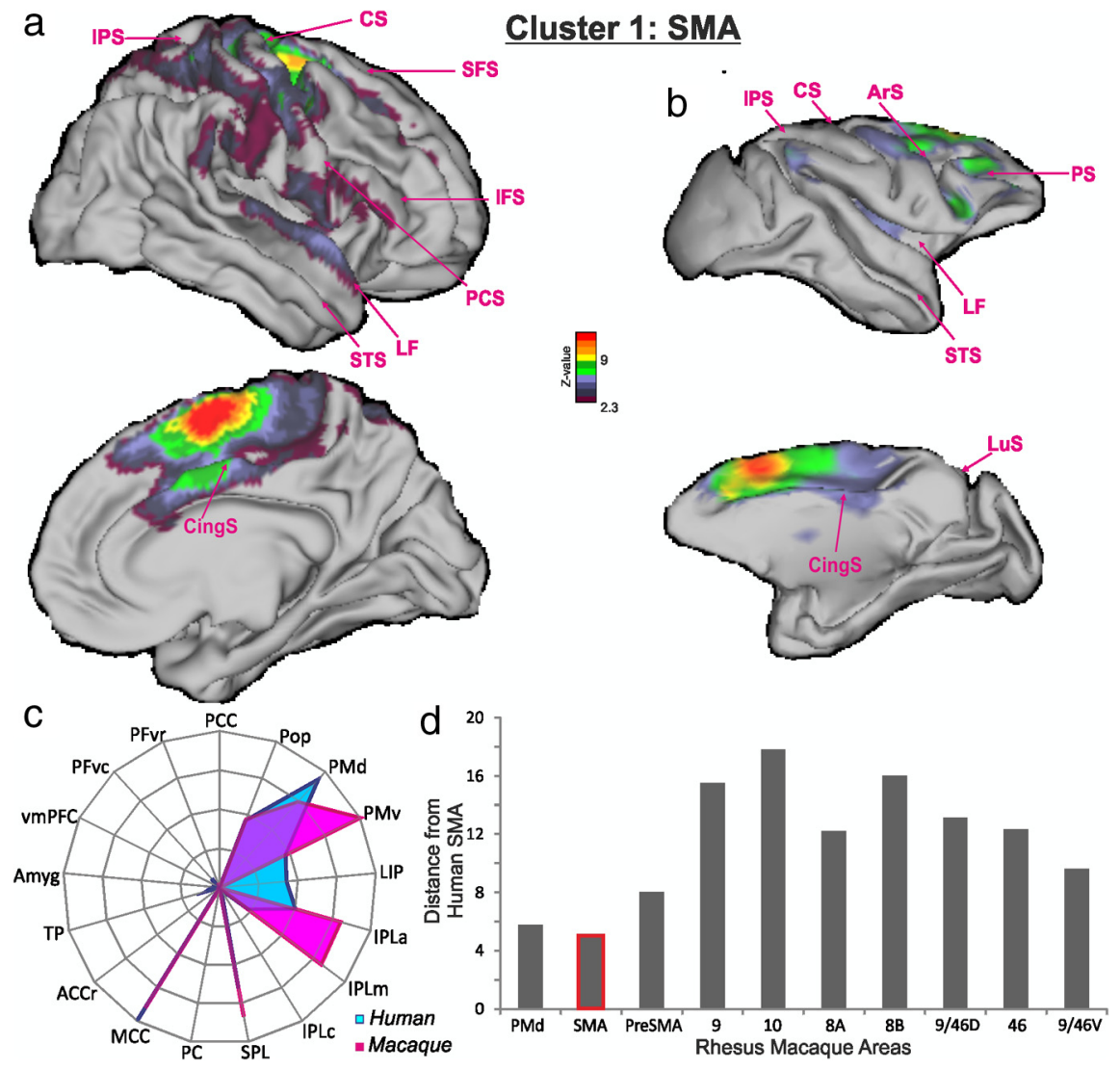

Figure 5. Cluster 1/SMA. $\boldsymbol{a}, \boldsymbol{b}$, The BOLD coupling patterns of cluster 1 in human subjects $(\boldsymbol{a})$ and SMA in macaques $(\boldsymbol{b})$ illustrated as $z$-statistic maps overlain on cortex. c, BOLD coupling patterns between human cluster 1 and macaque SMA and a set of regions in other parts of the brains in each species provided fingerprints of "functional connectivity." $\boldsymbol{d}$, The summed absolute differences between the functional coupling scores of human cluster 1 and 10 areas in macaque DFC suggested that the BOLD coupling pattern of human cluster 1 was least different to (in other words, it was most similar to) the coupling pattern associated with macaque SMA (lowest bar). Ars, Arcuate sulcus; CS, central sulcus; CingS, cingulate sulcus; IFS, inferior frontal sulcus; IPS, intraparietal sulcus; LF, lateral fissure; LuS, lunate sulcus; PCS, precentral sulcus; PS, principal sulcus; SFS, superior frontal sulcus.

nine-cluster parcellation. Following previous reports (Beckmann et al., 2009; Mars et al., 2011), each of these nine clusters was then reparcellated into subclusters in an attempt to search for any finer grain parcellation that could be seen consistently in all nine participants. It was found that three medial clusters and one lateral cluster could each be subdivided into two component clusters. However, as explained in detail in the Results the three most medial subclusters obtained in this way were positioned in the cingulate cortex and corresponded to cingulate areas that have been previously reported (Beckmann et al., 2009). The remaining 10 clusters in the frontal cortex are thus the focus of the present report (see Figs. 1, 3, 9, 18). Each of the participant's individual clusters was transformed from FreeSurfer space to the MNI template brain. The center of gravity of each cluster in MNI space was then established.

We note that the approach that we used in defining DFC clusters was similar to that taken previously in investigations of cingulate, parietal, and temporo-parietal junction cortex (Johansen-Berg et al., 2004; Tomassini et al., 2007; Beckmann et al., 2009; Mars et al., 2011, 2012a), but it constrains us to only identifying regions that have a consistent location in standard MNI space across subjects. This means that the DFC areas we delineate are likely to be the same ones that will figure in the results of task-based fMRI analyses in which effects are averaged over participants. Nevertheless, the DFC is likely to contain more spatially fine-grained levels of organization.

Confirmation of DW-MRI and tractography-based parcellation in an additional group of subjects. As explained above, the number of subjects examined in our DW-MRI tractography-based parcellation is approximately similar to the number of subjects studied in previous anatomical parcellation studies. Nevertheless, we sought to confirm the appropriateness of our parcellation scheme by attempting an analysis of an addi- tional group of 25 right-handed (according to Edinburgh Handedness Inventory: mean \pm SD, $77 \pm 26.7$ ) healthy human subjects ( $14 \mathrm{fe}$ males; age range, $20-45$ years; mean age, $29 \pm$ 6.6 years).

The data were acquired on a $3 \mathrm{~T}$ Siemens Magnetom Verio MR scanner. All participants gave written informed consent in accordance with ethical approval from the local ethics committee. Participants lay supine in the scanner, and cushions were used to reduce head motion. Diffusion-weighted data were acquired using EPI (65 2.0-mm-thick axial slices; field of view, $190 \times 190 \mathrm{~mm}^{2}$; voxel size, $2 \times$ $2 \times 2 \mathrm{~mm}$ ). Diffusion weighting was isotropically distributed along 60 directions using a $B$ value of $1.000 \mathrm{~s} / \mathrm{mm}^{-2}$. Eight volumes with no diffusion weighting were acquired throughout the acquisition. A structural scan was acquired for each participant in the same session, using a T1-weighted three-dimensional fast, low-angle shot (3D Multiecho MPRAGE) sequence (TR, $2530 \mathrm{~ms}$; TE, $1.69 \mathrm{~ms}$; flip angle, $7.0^{\circ}$; elliptical sampling of $k$ space, giving voxel size of $1.0 \times$ $1.0 \times 1.0 \mathrm{~mm}$ ).

The data were analyzed in a similar way to those obtained from the first nine subjects. For each participant, probabilistic tractography was run from each voxel in the right DFC ROI (the ROI was defined in standard MNI space, using the same criteria as described above, and then registered into each individual subject's MRI using FNIRT, a part of FSL) to assess connectivity with every brain voxel (down-sampled to $5 \mathrm{~mm}$ isotropic voxels), using a model accounting for multiple fiber orientations in each voxel (Behrens et al., 2007). To allow the clustering to be fully driven by the connectivity with the rest of the brain, no connexity constraint was applied during this clustering procedure (Tomassini et al., 2007). We then performed a cross-correlation analysis on the obtained connectivity matrix. The rows of this cross-correlation matrix were then permuted using a fuzzy $k$-means $(k=10)$ algorithm for automated clustering to define 10 different clusters as an attempt to replicate the results we obtained in the analysis of our nine subjects. Note that in addition to examining the right DFC we also performed an additional analysis on the left DFC.

Human resting-state $\mathrm{fMRI}$ data acquisition and preprocessing. Restingstate $\mathrm{PMRI}$ and structural MRI data were collected from 36 human subjects (15 females; average age, 28.5 years) on a Siemens 3T TIM Trio scanner (Filippini et al., 2009). This group of participants was a distinct group from those taking part in the DW-MRI experiment. All participants gave informed written consent in accordance with ethical approval from the local ethics committee.

For the resting-state fMRI scan, subjects were instructed to lie in dimmed light with their eyes open, to think of nothing in particular, and not to fall asleep. Whole-brain functional imaging was performed using a gradient echo EPI sequence $\left(\mathrm{TR}=2000 \mathrm{~ms} ; \mathrm{TE}=28 \mathrm{~ms}\right.$; flip angle $=89^{\circ}$; field of view $=224 \mathrm{~mm}$; voxel dimension $=3 \times 3 \times 3.5 \mathrm{~mm}$; acquisition time $=6 \mathrm{~min} 4 \mathrm{~s}$ ). High-resolution 3D T1-weighted MRI scans were also acquired using a magnetization prepared rapid gradient echo sequence $\left(\mathrm{TR}=2040 \mathrm{~ms} ; \mathrm{TE}=4.7 \mathrm{~ms}\right.$; flip angle $=8^{\circ}$; field of view $=192 \mathrm{~mm}$; voxel dimension $=1 \mathrm{~mm}$ isotropic; acquisition time $=12 \mathrm{~min}$ ).

Data were analyzed using tools from FSL (Smith et al., 2004) and custom tools written in Matlab, and were visualized using the Connectome Workbench. The first six volumes of each functional dataset were discarded, after which the following preprocessing was performed: motion correction, nonbrain removal, spatial smoothing (using Gaussian 5 mm FWHM kernel), grand-mean intensity normalization of the entire 
four-dimensional (4D) dataset by a single multiplicative factor, high-pass temporal filtering (Gaussian-weighted least-squares straight-line fitting, with $\sigma=50.0 \mathrm{~s}$ ). Registration of functional images to the skull-stripped structural template was done using FLIRT (Jenkinson et al., 2002).

Macaque resting-state fMRI data acquisition and preprocessing. Macaque $\mathrm{fMRI}$ and anatomical scans were collected for 20 healthy macaque monkeys (Macaca mulatta, six females; average age, 4.38 years; average weight, 6.53 $\mathrm{kg})$. Protocols for animal care, magnetic resonance imaging, and anesthesia were performed under authority of personal and project licenses in accordance with the UK Animals (Scientific Procedures) Act (1986). Anesthesia was induced using intramuscular injection of ketamine $(10 \mathrm{mg} / \mathrm{kg})$ combined with either $\mathrm{xy}$ lazine $(0.125-0.25 \mathrm{mg} / \mathrm{kg})$ or midazolam $(0.1$ $\mathrm{mg} / \mathrm{kg})$ and buprenorphine $(0.01 \mathrm{mg} / \mathrm{kg})$. Macaques also received injections of atropine (0.05 mg/kg, i.m.), meloxicam $(0.2 \mathrm{mg} / \mathrm{kg}$, i.v.), and ranitidine $(0.05 \mathrm{mg} / \mathrm{kg}$, i.v.). Local anesthetic (5\% lidocaine/prilocaine cream and $2.5 \%$ bupivacaine injected subcutaneously around the ears to block peripheral nerve stimulation) was also used at least $15 \mathrm{~min}$ before placing the macaque in the stereotaxic frame. Anesthesia was maintained with isoflurane. The anesthetized animals were placed in an MRI-compatible stereotactic frame (Crist Instrument) in a sphinx position within a horizontal 3T MRI scanner with a full-size bore. Scanning commenced $\sim 1.5-2 \mathrm{~h}$ after induction, when the peak effect of ketamine was unlikely still to be present. In accordance with veterinary instruction, anesthesia was maintained using the lowest possible concentration of isoflurane gas. The depth of anesthesia was assessed using physiological parameters (continuous monitoring of heart rate and blood pressure as well as clinical checks for muscle relaxation before scanning). During the acquisition of the MRI data, the mean inspired isoflurane concentration was $1.48 \%$ (SD, $0.38 \%$ ), and the mean expired isoflurane concentration was $1.41 \%$ (SD, $0.33 \%)$. Isoflurane was selected for the scans as resting-state networks have previously been demonstrated to be present using this agent (Vincent et al., 2007; Mars et al., 2011; Sallet et al., 2011; Hutchison et al., 2012b). Vincent et al. (2007) reported similar patterns of functional coupling between brain areas at two levels of isoflurane, $0.9 \%$ and $1.25 \%$, that were similar to the levels that we used. They therefore amalgamated results collected "at isoflurane levels between $0.8 \%$ and 1.5\%." In other words, they used a range of isoflurane levels that were similar to the ones that we used. We note that our intention was to equate the levels of physiological anesthesia across animals and not the level of anesthetic gas concentration. Slight individual differences in physiology mean that slight differences in anesthetic gas concentrations are needed to impose a similar level of anesthesia on different monkeys. Macaques were maintained with intermittent positive-pressure ventilation to ensure a constant respiration rate (mean rate, 22 breaths/min; SD, 3.15 breaths/min) during the functional scan. Respiration rate, inspired and expired $\mathrm{CO}_{2}$, and inspired and expired isoflurane concentration were monitored and recorded using VitalMonitor software (Vetronic Services). In addition to these parameters, core temperature was monitored using an Opsens temperature sensor, and pulse rate (mean rate, 103.75 beats/min; SD, 9.2 beats/min) and $\mathrm{O}_{2}$ saturation ( $\left.>95 \%\right)$ were monitored using a Nonin Medical sensor throughout the scan.

A four-channel, phased-array, radio-frequency coil in conjunction with a local transmission coil was used for data acquisition (Windmiller Kolster Scientific). Whole-brain BOLD fMRI data were collected for 53 min and $26 \mathrm{~s}$ from each animal, using the following parameters: 36 axial slices; in-plane resolution, $2 \times 2 \mathrm{~mm}$; slice thickness, $2 \mathrm{~mm}$; no slice gap; $\mathrm{TR}=2000 \mathrm{~ms} ; \mathrm{TE}=19 \mathrm{~ms} ; 1600$ volumes. Structural scans were acquired for each macaque in the same session, using a T1-weighted MPRAGE sequence $($ no slice gap; $0.5 \times 0.5 \times 0.5 \mathrm{~mm} ; \mathrm{TR}=2500 \mathrm{~ms} ; \mathrm{TE}=$ $4.01 \mathrm{~ms} ; 128$ slices).

Data were analyzed using tools from FSL (Smith et al., 2004) and custom tools written in Matlab (Mathworks), and were visualized using Caret (Van Essen et al., 2001) and the Connectome Workbench (http://www.humanconnectome.org). The first six volumes of each functional dataset were discarded, and the following preprocessing was performed: nonbrain removal, $0.1 \mathrm{~Hz}$ low-pass filtering to remove respiratory artifacts, motion correction, spatial smoothing (using Gaussian 3 $\mathrm{mm}$ FWHM kernel), grand-mean intensity normalization of the entire 4D dataset by a single multiplicative factor, high-pass temporal filtering (Gaussian-weighted least-squares straight-line fitting, with $\sigma=50.0 \mathrm{~s}$ ). Registration of functional images to the skull-stripped structural image and a macaque template was performed using FLIRT (Jenkinson et al., 2002).

Comparing resting-state $f M R I$ data between species. To quantify differences between the functional connectivity patterns of the prefrontal areas yielded by the tractography-based parcellation, we created a number of target ROIs and examined DFC coupling with these regions in both humans and macaques.

The human DFC regions that we examined were the ones that resulted from the DW-MRI-based tractography experiment (Fig. 2a-c). The DFC regions $(4 \times 4 \times 4 \mathrm{~mm}$ cubes $)$ were placed at each DFC cluster's center of gravity. Occasionally, because of the convex geometry of the cortex, a region's center of gravity lay just inside the white matter rather than within the gray matter itself. Therefore, the DFC coordinates that were used were ones that were moved slightly to ensure that they were not in 


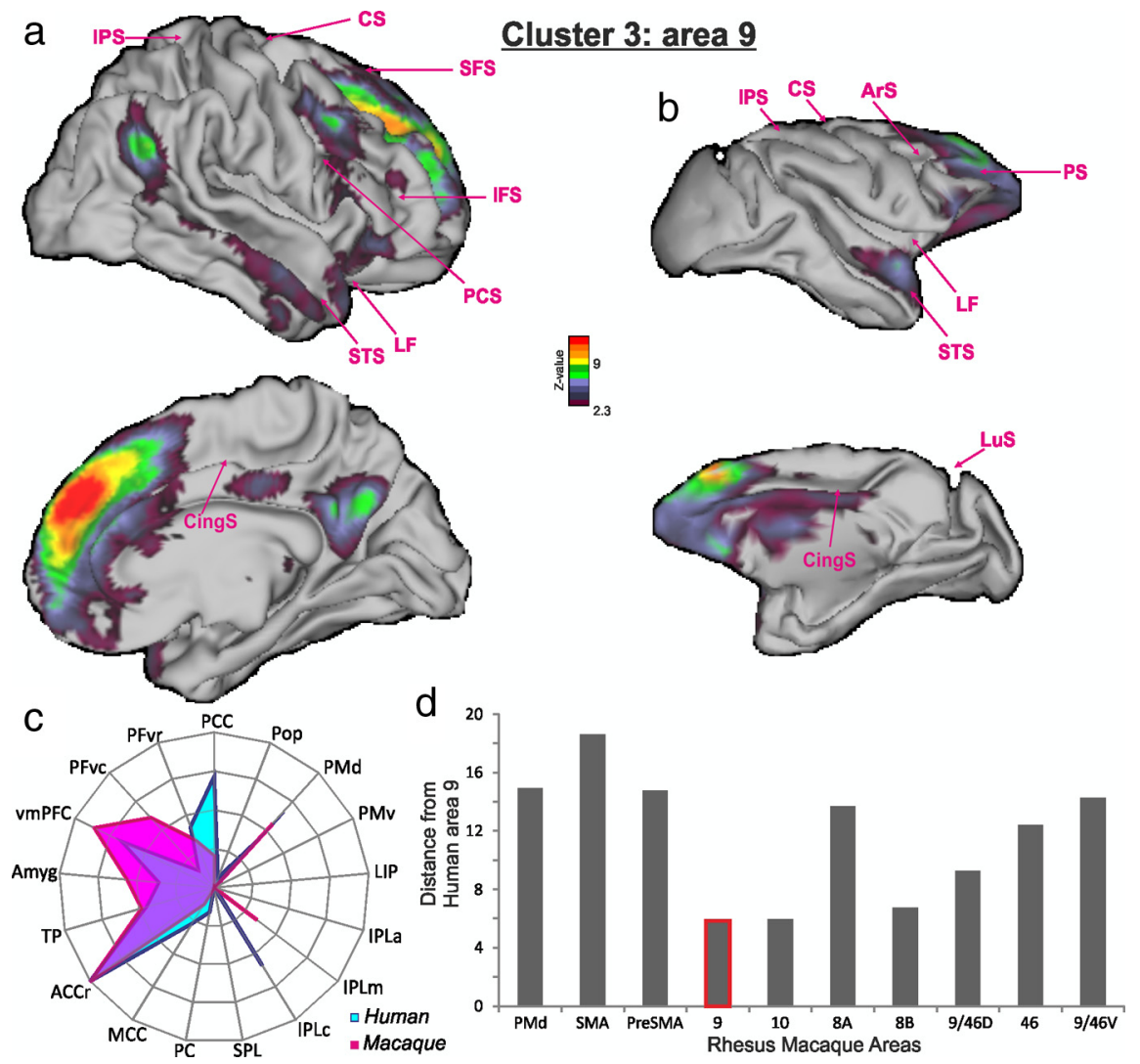

Figure 7. Cluster 3/area 9. $\boldsymbol{a}-\boldsymbol{c}$, The BOLD coupling patterns of cluster 3 in human subjects $(\boldsymbol{a})$ and area 9 in macaques $(\boldsymbol{b})$ and their associated functional connectivity fingerprints in humans and macaques $(\boldsymbol{c})$. $\boldsymbol{d}$, The summed absolute differences between the functional coupling scores suggested that human cluster 3 resembled macaque area 9 (lowest bar). All other conventions are as in Figure 5.

white matter but at the nearest point at which there was high betweensubject overlap in gray matter. The regions of interest (with MNI coordinates, $x, y, z)$ were located at cluster $1[8,4,58]$, cluster $2[5,24,50]$, cluster $3[6,48,29]$, cluster $4[4,58,6]$, cluster $5[29,40,39]$, cluster $6[45$, $28,26]$, cluster $7[28,48,15]$, cluster $8[30,5,49]$, cluster $9[23,0,51]$, and cluster $10[24,32,38]$.

We performed a similar analysis in macaque monkeys (Fig. $2 d-f$ ); we identified brain regions where the BOLD signal at rest was correlated with the BOLD signal in each of 10 frontal areas in the macaque monkey that might correspond to the human DFC regions we had identified. Because of the extreme difficulty of obtaining the very high-spatial resolution DW-MRI data that would be required to conduct a tractographybased parcellation of the relatively small macaque brain in vivo and because the positions of cytoarchitectonically defined areas are reasonably well established in the macaque, we examined the coupling patterns of BOLD signals in four cytoarchitectonically defined areas of the macaque brain. A region of interest $(0.75 \times 0.75 \times 0.75 \mathrm{~mm}$ cubes $)$ was placed in the cortex of the supplementary motor area (SMA), pre-SMA, area 9 , area 10 , area $8 \mathrm{~A}$, anterior dorsal premotor cortex $(\mathrm{PMd})$, area $8 \mathrm{~B}$, area $9 / 46 \mathrm{~d}$, area $9 / 46 \mathrm{v}$, and area 46 at macaque MNI coordinates $(x, y, z)$ (Frey et al., 2011) [0.87, 1.62, 19.31], [0.87, 9.37, 16], [1.06, 15.12, 14.18], $[2.62,26.127 .68],[15.5,8.2,11.43],[7.87,11.62,15.62],[9.12,16.37$, $13.18],[12.87,14.37,11.56],[14.87,14.62,8.37]$, and [11.12, 11.37, 8.87] respectively.

Because our intention was to compare the BOLD coupling patterns of human dorsal premotor cortex an and macaque DFC, we focused on the coupling patterns between each DFC cluster and ROIs in other brain areas that met two criteria (Fig. 2). First, the ROIs were ones that are known to be connected to prefrontal cortex in the macaque. Second, the ROIs were ones that could be identified in both humans and macaques and are known to be homologous. This meant, for example, that we did not look at dorsal frontal coupling with areas such as the superior tem- poral sulcus (STS); this area is known to be connected with DFC in macaques, but interspecies neuroanatomical correspondences in this region are uncertain. For this reason, comparing the functional coupling of the STS in the context of the current experiment is less informative because there are good reasons to think that we would not be comparing like with like.

The cubic ROIs were placed in the ventral premotor cortex (PMv) centered at MNI coordinates $[61,9,31]$, the PMd centered at $[37,1$, 48], the rostral ventral prefrontal cortex (PFvr) centered at $[39,39,-15]$, the caudal ventral prefrontal cortex (posterior PFvc) centered at $[49,31,19]$, the ventromedial prefrontal cortex (vmPFC) centered at $[3,47,-7]$, the rostral anterior cingulate cortex (ACCr) centered at $[5,49,5]$, the mid-cingulate cortex (MCC) centered at $[3,-9,43]$, the posterior cingulate cortex (PCC) centered at $[5,-49,17]$, the caudal inferior parietal lobule (IPLc) centered at $[45,-75,35]$, the mid-section of the IPL (IPLm) centered at $[51,-43,47]$, the rostral IPL (IPLr) centered at $[57,-33,45]$, the lateral intraparietal area (LIP) centered at $[21,-65$, 57], the superior parietal lobule (SPL) centered at $[19,-57,65]$, the medial parietal cortex in the precuneus (PC) centered at $[5,-59,47]$, the parietal operculum (POp) centered at [53, $-17,17]$, the temporal pole (TP) centered at $[39,-9,-17]$, and the amygdala centered at $[-17,-9,-17]$. All masks were of identical size $(4 \times 4 \times 4 \mathrm{~mm})$, so as not to bias the analysis.

Equivalent cubic target masks were created on the macaque template brain using the MNI rhesus monkey atlas (Frey et al., 2011) at the following coordinates: PMv centered at [17 5.5 10.75], PMd centered at $[7,5.75,16.5]$, PFvr centered at $[11.5,21.75$, 4.75], PFvc centered at $[17.25,15.25,8]$, vmPFC centered at $[0.75,21.5$, 1.75], ACCr centered at $[1,20.75,6]$, MCC centered at $[2.75,-8.25$, 15.25], PCC centered at $[1.5,-18,6]$, IPLc centered at $[9.5,-24.75,19]$, IPLm centered at $[15,-21,19]$, IPLr centered at $[17,-15.25,17]$, LIP centered at $[6,-23.25,16.25]$, SPL centered at $[4,-20,23.25]$, PC centered at $[1.25,-24.75,13.5]$, POp centered at $[21.5,-6,8.75]$, TP centered at $[15.75,6.25,-14.75]$, and the amygdala centered at $[-10.5,1.75$, $-10.5]$. All masks were of identical size $(0.75 \times 0.75 \times 0.75 \mathrm{~mm})$.

Anatomical and functional evidence suggests that there are homologies between each of these target regions in humans and macaques: PMd and PMv (Passingham et al., 1998; Geyer et al., 2000; Passingham and Toni, 2001; Picard and Strick, 2001; Tomassini et al., 2007); LIP, SPL, and PC (Rushworth et al., 2001; Sereno et al., 2001; Astafiev et al., 2003; Grefkes and Fink, 2005; Swisher et al., 2007; Scheperjans et al., 2008b; Hinkley et al., 2009; Margulies et al., 2009; Mars et al., 2011); IPLc, IPLm, IPLr, and POp (Culham et al., 2003; Caspers et al., 2006, 2008, 2011; Eickhoff et al., 2010; Mars et al., 2011); PFvr, PFvc, and vmPFC (Petrides and Pandya, 2002, 2009; Petrides, 2005; Mackey and Petrides, 2010); ACCr, MCC, and PCC (Picard and Strick, 1996, 2001; Margulies et al., 2009; Vogt, 2009; Amiez and Petrides, 2012); TP (Blaizot et al., 2010); and amygdala (Aggleton, 2000).

We used a voxelwise approach to map resting-state functional connectivity between each prefrontal cortex cluster and characteristic time series associated with specific target regions. This analysis was performed both in the human and in the macaque. This means that it is possible to compare the resting-state functional connectivity of the macaque DFC with the known structural connectivity of the DFC that has been established in tract tracing experiments. Then, by comparing the functional interactions between the macaque and human brain, we can directly compare the organization of the DFC between the two species using the 
same technique. First, we calculated the major Eigen time series around the center of each of the human clusters resulting from the tractography-based parcellation and their macaque equivalents. The major Eigen time series is the single time series that best reflects coherent activity across the mask in that it represents the largest amount of variance across the set of voxels within the region. Using a seed-based correlation analysis tool of FSL, we then calculated the correlation of each gray matter voxel while accounting for the average time series of the whole brain and the six movement parameters; a procedure that allows us to make comparison between the datasets from the two species (Mars et al., 2011). The resulting correlation masks were then entered into a nonparametric second-level group analysis performed using the FSL tool fsl_glm. This procedure was done for each frontal region separately and resulted in a $z$-statistical map for each region. These maps are displayed in Figures 5, 6, 7, 8, $10,11,12,14$, and 15 (thresholded at $z>2.3$ for display purposes only).

Having established the reliability of the resting-state fMRI method and compared the patterns of correlation between the macaque and human brains, we then sought to formally compare the pattern of resting-state functional connectivity associated with each of the DFC clusters with the target areas outside of DFC and so to create a resting-state connectivity fingerprint for each DFC cluster (Passingham et al., 2002). The strength of BOLD coupling between each DFC region and each target area was determined by masking the thresholded $(\geq 0)$ resting-state functional correlation map of each DFC cluster with each of the target regions of interest described at the beginning of this section. The average positive resulting $z$-score in each target mask was then calculated and taken as an index of connectivity between the target mask area and the respective frontal area. For each DFC area, a vector can then be created that contains the coupling of that area with each of the target areas. This vector can be represented as a spider plot (Figs. 5, 6, 7, 8, 10, 11, 12, 14, and 15). Such fingerprints have previously been used to compare connections and coupling between other brain regions (Passingham et al., 2002; Tomassini et al., 2007; Beckmann et al., 2009; Mars et al., 2011). Note that the areas that we investigate in such fingerprints are mostly in the premotor, parietal, frontal, and cingulate areas rather in the temporal cortex. This is because such connections are more diagnostic (Preuss, 1995) of similarities in coupling patterns in species, whereas we know that there has been major reorganization within the temporal cortex in humans and macaques (Van Essen and Dierker, 2007). To be able to compare fingerprints between the human and macaque datasets, which cannot be expected to have an equal signal-to-noise ratio, the connectivity fingerprints were normalized such that the maximum connectivity between the given DFC area and any of its target regions has a value of 1 and the minimum connectivity between the given DFC area and any of its target regions has a value of 0 .

We then illustrated the dissimilarity or "distance" between a human frontal area's coupling fingerprint and the coupling fingerprint associated with each frontal area of the macaque so as to make a formal comparison between the human and macaque coupling patterns. We computed the summed absolute difference, sometimes called the "Manhattan" or "city-block" distance index (Krause, 1987), between the normalized functional connectivity fingerprints to summarize differences in the BOLD coupling patterns between each human DFC cluster with DFC regions in the macaque. This summary measure can then be used to compare the functional coupling pattern of each human DFC region with the functional coupling patterns associated with all 10 DFC regions in the macaque. For each human DFC region, we show a bar chart where the height of each bar represents the distance between the connectivity fingerprints of the human DFC region in question and all macaque DFC regions. The lowest bar (highlighted in pink) indicates the macaque area that is least different (most similar) to the human DFC area investigated in terms of its coupling patterns with the rest of the brain. The results for the various areas are summarized in panel $d$ of Figures 5, 6, 7, 8, 10, 11, 12, 14 , and 15 . Note that once again in these analyses, as in other illustrations of inter-regional BOLD coupling and as in the fingerprint graphs, we focus on positive BOLD coupling effects.

We note that previous studies of areas of the human and macaque parietal and posterior cingulate cortex that are thought to be similar on cytoarchitectonic grounds have similar patterns of BOLD signal coupling. These coupling patterns appear similar regardless of whether data are collected while subjects are awake or under anesthesia (Vincent et al., 2007; Margulies et al., 2009; Mars et al., 2011; Hutchison et al., 2012a).

\section{Results}

Tractography-based parcellation of DFC identified 10 clusters that were consistently located in similar positions in MNI space in all subjects. Two control procedures suggested that these were some of the key subregions into which DFC could be subdivided. First, the clusters that were identified when a finer parcellation of the DFC into more areas was attempted were not consistently located across subjects. Second, a series of attempts were made to further parcellate each of the regions that were found in the initial analysis into additional, smaller subregions. Again, the clusters reported here could not be reliably parcellated further. In what 
a Cluster 5: Area 9/46d

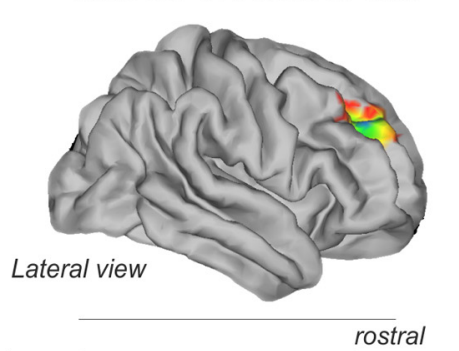

b Cluster 6: Area 9/46v

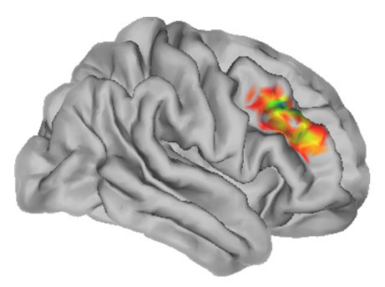

C Cluster 7: Area 46
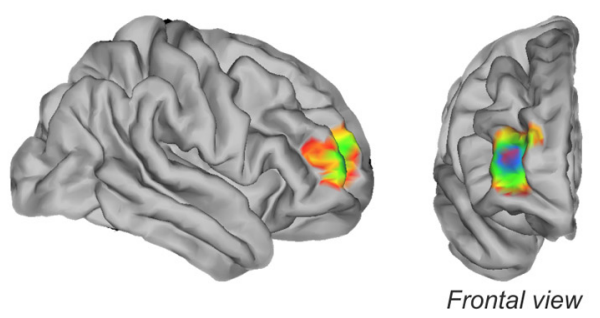

d Cluster 8: Area 8A
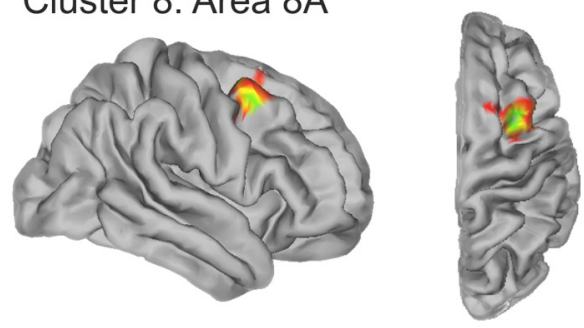

e Cluster 9: PMd
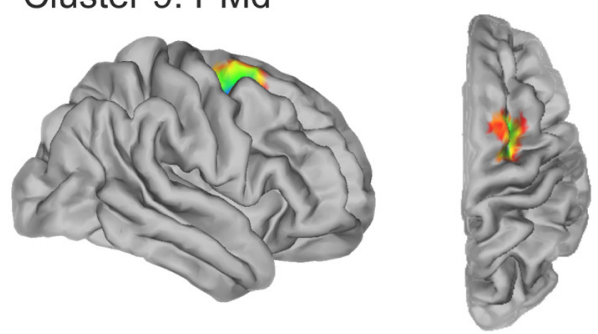

f Cluster 10: Area 8B

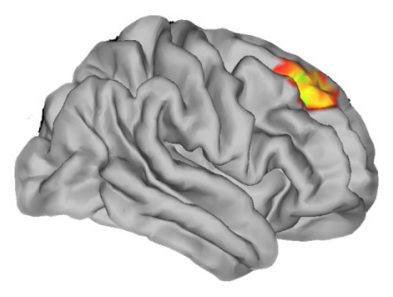

39

Nb Subjects follows, we summarize the results for the medial frontal cortex first and then results in the lateral frontal cortex.

\section{Four clusters in dorsomedial frontal cortex}

The initial tractography-based parcellation identified four areas in the medial frontal cortex dorsal to ACC (Fig. 3). The most posterior area, cluster 1 , had a center of gravity at $[10,4,59]$ and occupied a similar area to the SMA that is active when people make simple movements, for example, during finger tapping (Johansen-Berg et al., 2004) (Fig. 3a). The center of gravity of the cluster meant that it was just anterior to the center of the SMA that has been previously reported, although it lay within the same range (Johansen-Berg et al., 2004; Mayka et al., 2006). It is likely that our estimate of the position of the region is biased in the anterior direction because the initial volume we attempted to parcellate was bounded at the level of the superior precentral sulcus at approximately $y=-10$; it was therefore unlikely to have included the whole of the SMA. There is evidence that a more anterior subcomponent may exist within SMA (Vorobiev et al., 1998), and it is possible that our analysis focuses on this region. In the monkey, the connections of the SMA with primary motor cortex and ventral horn of the spinal cord have meant that it is included among the motor association or premotor areas (Strick et al., 1998; Geyer et al., 2000).

A second cluster, cluster 2, was identified just anterior to cluster 1 at $[14,23,52]$. It was situated on the medial surface, but it extended over the crown onto the lateral surface of the posterior superior frontal gyrus. It therefore lay in approximately the same position as the pre-SMA, a region important during the initiation and changing of actions (Johansen-Berg et al., 2004; Rushworth, 2008) (Fig. 3b). The center of gravity of the cluster meant that it was just anterior to what has been previously reported (JohansenBerg et al., 2004). It is possible that the relatively posterior setting of the anterior boundary of the region investigated in previous studies may have induced a posterior bias in previous estimates. The pre-SMA lacks the direct connections that the SMA has with the primary motor cortex and ventral horn of the spinal cord, and so it is not classified as a premotor area. Instead, its transitional nature between motor and prefrontal cortex is emphasized (Picard and Strick, 2001). Like premotor areas, however, it is still able to influence primary motor cortical activity and behavior at short latencies (Taylor et al., 2007; Mars et al., 2009; Neubert et al., 2010).

Cluster 3 was situated even more anteriorly with a center of gravity at $[10,50,29]$. It was mainly situated on the medial surface, but it extended over the crown and onto the superior frontal gyrus. It therefore appears to lie in the same position as the cytoarchitectonically defined prefrontal area 9 (Petrides and Pandya, 1999; Petrides, 2005), although a description of the location of area 9 with respect to MNI coordinates has not been published (Fig. $3 c$ ). One of the most prominent and consistent findings in fMRI studies of this region is its activation in social cognitive tasks in which subjects attempt to infer the intentions or beliefs of others (Amodio and Frith, 2006; Behrens et al., 2008, 2009;

$\leftarrow$

Figure 9. Tractography-based parcellation revealed six clusters in human dorsolateral frontal cortex. $\boldsymbol{a}-\boldsymbol{f}$, In each case, the clusters' topological position and BOLD coupling patterns with other brain regions suggested similarities with particular areas of macaque DFC: cluster 5 resembled area 9/46d (a), cluster 6 resembled area $9 / 46 \mathrm{v}(\boldsymbol{b})$, cluster 7 resembled area $46(\boldsymbol{c})$, cluster 8 resembled $8 \mathrm{~A}(\boldsymbol{d})$, cluster 9 resembled rostral PMd $(\boldsymbol{e})$, and cluster 10 resembled area $8 \mathrm{~B}(\boldsymbol{f})$. All other conventions are as in Figure 5. 
Hampton et al., 2008). Such tasks are sometimes referred to as theory of mind and "mentalizing tasks."

The most anterior area, cluster 4, on the medial surface had a center of gravity at $[16,58,4]$, where it occupied a similar location to the one proposed for frontal polar area 10 (Petrides and Pandya, 1999; Petrides, 2005), although, once again, the boundaries and center of gravity of a cytoarchitectonically defined area 10 in MNI space have not been published (Fig. $3 d$ ). Again, activity in this region is associated with social cognitive processes such as mentalizing (Amodio and Frith, 2006; Gilbert et al., 2006; Yoshida et al., 2010). Different subdivisions of area 10 have been proposed on the basis of neuroimaging investigations, and the region corresponds to what some authors refer to as the medial part of area 10 (Gilbert et al., 2006). No consistent subdivision, however, was identifiable within the area 10like cluster 4 in our study. Below, we argue that cluster 4 may in fact constitute the entirety of area 10 (at least in DFC as opposed to more ventral frontal cortex). We argue that the area that lies laterally adjacent to it may be a very distinct cortical region that more closely corresponds to area 46.

\section{The ventral border between the dorsomedial clusters and the cingulate cortex}

As already noted, the tractography-based parcellation identified four clusters in the medial frontal cortex. In this section, we report how we performed a further search for consistently positioned subregions within each of the medial frontal clusters. In other words, we attempted a further parcellation of each of the four clusters that we had already identified. The additional analyses were prompted partly by a desire to characterize DFC as fully as possible and also by a desire to better characterize the border between dorsal frontal areas that we investigate here (SMA, preSMA, area 9, and area 10) and the more ventral ACC.

When a further parcellation attempt was performed on each of the four medial frontal areas, we were unable to identify any consistent subdivision within cluster 4 , but it was possible to identify evidence for more ventral and more dorsal subdivisions in each of the three more posterior clusters, 1, 2, and 3 (Fig. 4). As explained in detail in the previous section, the centers of gravities of the dorsal regions identified them with SMA, pre-SMA, and area 9 . We previously reported a tractography-based parcellation of the human anterior cingulate cortex ventral to the fundus of the paracingulate sulcus/dorsal bank of the cingulate sulcus (Beckmann et al., 2009). The positions of all three ventral regions in the present study overlapped with our previously described regions in ACC (Beckmann et al., 2009). Together, the present study and the previous study of Beckmann et al. (2009) identify eight principle regions in dorsomedial frontal cortex: a ventral tier of cingulate areas, including the cingulate motor areas and area 32; and a dorsal tier of SMA, pre-SMA, area 9, and area 10.
Because the ACC regions have been described previously, we focused here on the dorsal tier of areas.

\section{Functional coupling of dorsomedial frontal cortex in humans} and macaques

The pattern of BOLD signal coupling seen between the human SMA-like cluster 1 and the rest of the brain was quite distinct to that seen when the other dorsal frontal areas were investigated (Fig. 5a). It did, however, resemble that seen when the resting BOLD coupling patterns of SMA were examined in the macaque (Fig. $5 b-d$ ). In both cases, there was a correlated BOLD signal in a number of motor-related areas on the lateral and medial surface including the cingulate motor regions and SPL. This cluster showed only moderate coupling with other prefrontal clusters and with the temporal lobe. The pattern of coupling resembles the connections that are known to exist from tracer injection studies between the SMA and the same regions in the macaque (McGuire et al., 1991; Luppino et al., 1993; Petrides and Pandya, 1999; Dum and Strick, 2005; Miyachi et al., 2005).

The human pre-SMA-like cluster 2 (Fig. $6 a$ ) and the macaque pre-SMA region (Fig. $6 b$ ) exhibited similar patterns of BOLD coupling to one another (Fig. $6 c, d$ ). In contrast to the SMA, there was evidence of much more extensive coupling between this region and prefrontal cortex, apparent throughout a wide swathe of medial and lateral dorsal prefrontal cortex. The pre-SMA/cluster 2 BOLD signal was coupled with the BOLD signal in premotor areas, but coupling was strongest in more anterior parts of the premotor cortex than had been the case for SMA/cluster 1. The pattern resembles the distribution of connections of the pre-SMA 


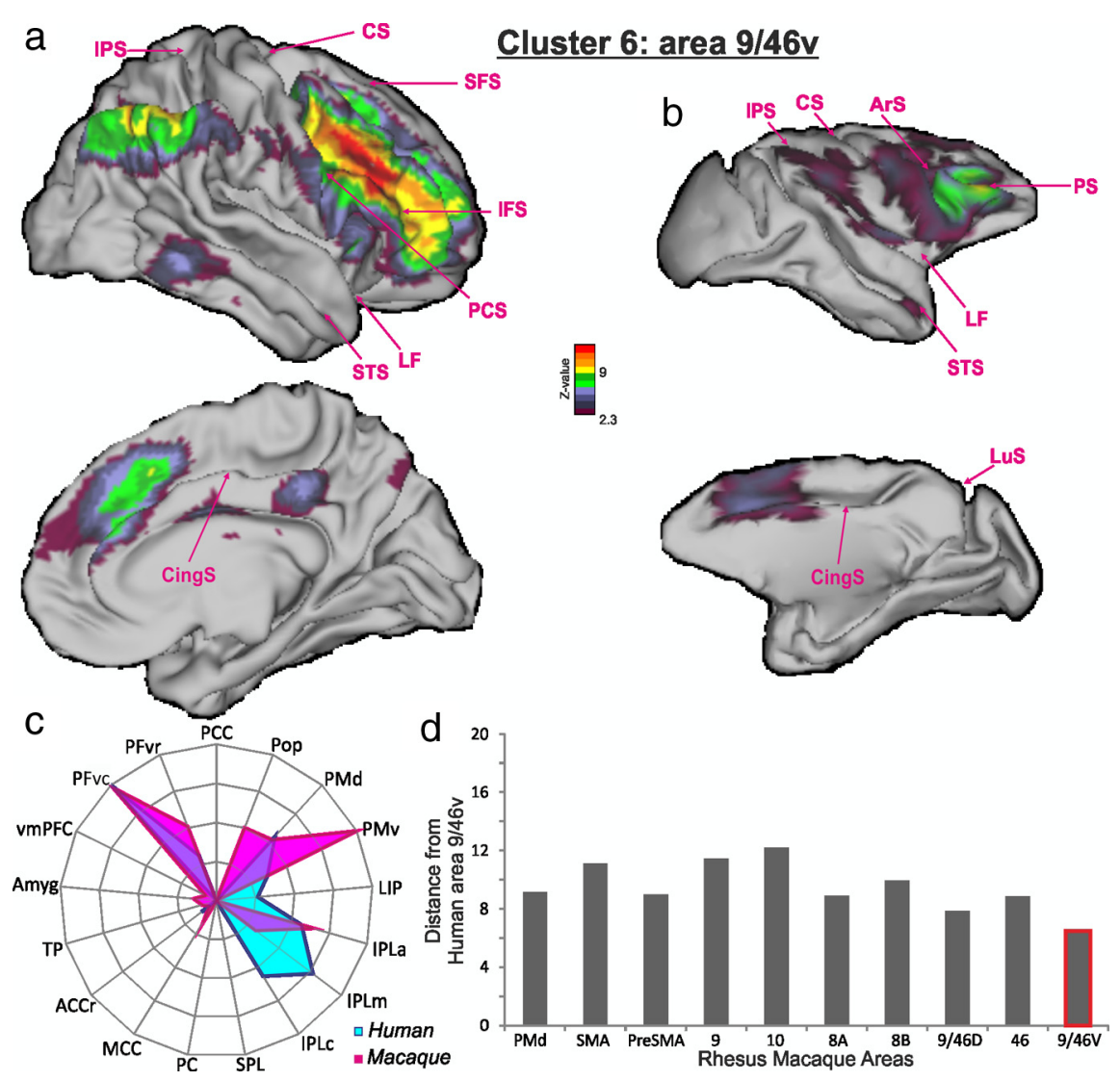

Figure 11. Cluster 6/area 9/46v. $\boldsymbol{a}-\boldsymbol{c}$, The BOLD coupling patterns of cluster 6 in human subjects (a) and area 9/46v in macaques $(\boldsymbol{b})$ and their associated functional connectivity fingerprints in humans and macaques $(\boldsymbol{c})$. $\boldsymbol{d}$, The summed absolute differences between the functional coupling scores suggested that human cluster 6 resembled macaque area 9/46v (lowest bar). All other conventions are as in Figure 5.

in tracer injection studies of the macaque brain, and the differences between the SMA/cluster and the pre-SMA/cluster 2 coupling patterns resemble differences in SMA versus pre-SMA connections in the macaque (Bates and Goldman-Rakic, 1993; Luppino et al., 1993).

Once again, there were similarities between the BOLD coupling patterns of the human area 9-like cluster 3 and the macaque area 9 region (Fig. 7), and once again these patterns were distinct to those associated with SMA/cluster 1 and pre-SMA/cluster 2. The BOLD signal of area 9/cluster 3 was coupled with the BOLD signal in anterior PMd, as had been the case for pre-SMA/cluster 2. Unlike the previous two clusters, however, area $9 /$ cluster 3 BOLD, in both humans and macaques, was coupled with the BOLD signal throughout much of the frontal cortex; although it was especially prominent in the dorsal prefrontal cortex, it also extended into parts of ACC and vmPFC in both species. Moreover, in both species, there was less evidence of coupling between area9/cluster 3 and parietal cortex; instead, there was evidence of coupling with temporal cortex. In macaques, coupling was apparent in the anterior superior temporal gyrus, superior temporal sulcus, and TP, and in human subjects coupling was also evident in similar anterior, superior temporal cortex, and TP. Finally, there was evidence of BOLD coupling between area 9/cluster 3 and the amygdala in both species. The BOLD coupling with the amygdala and TP was a distinctive feature of area 9/cluster 3 that was seen in only one other area (area 10/cluster 4). All of these features of the coupling pattern of area 9/cluster 3 are reminiscent of the connection patterns of area 9 in the macaque (Morris et al.,
1999; Kobayashi and Amaral, 2003; Ghashghaei et al., 2007; Petrides and Pandya, 2007).

The most anterior medial frontal area, area 10/cluster 4 exhibited a coupling pattern that was similar in the two species (Fig. 8). Like area 9/cluster 3, the BOLD signal of area $10 /$ cluster 4 was coupled with the BOLD signal throughout much of prefrontal cortex including parts of ACCr and vmPFC. There was also coupling with the temporal cortex, especially in the anterior temporal sulcus and TP, in both species. There was evidence of BOLD coupling between area 10/cluster 4 and the amygdala in both species. Although area 10/cluster 4 shared with area 9/cluster 3 a distinctive pattern of coupling with TP and amygdale, there were differences between the coupling patterns of the two regions; there was comparatively little evidence of coupling between area 10/cluster 4 and premotor cortex in either species.

In a previous study, Goulas et al. (2012) have also suggested locations for regions that they argue might correspond to human areas 9 and 10 . The focus of their investigation was, however, ventral and posterior to the regions that we identified as areas 9 and 10. Instead, they argue that a region that lies more ventrolaterally than our cluster 3/area 9 , in a location that is lateral to the superior frontal sulcus and close to our cluster 10 (see below), corresponds to area 9. It seems unlikely that that this region could be area 9, given that we show below that there is BOLD signal coupling between it, but not cluster 3, and several parts of the IPL, while we show that cluster 3 is coupled with the temporal pole and amygdala. In other words, the coupling pattern associated with our cluster 3, rather than the region Goulas et al. (2012) suggest, is more reminiscent of area 9 in the macaque. Goulas et al. (2012) also suggest that a comparatively posterior, small region might correspond to human area 10 . One possibility is that the area they identify is a very posterior part of area 10; however, it lacked some of the distinctive coupling that our cluster 3/area 10 had with the temporal pole, which is also found in the macaque (Petrides and Pandya, 2007; Markov et al., 2012), and instead it had stronger coupling with the IPL, which our cluster 3/area 10 lacked, as does area 10 in the macaque (Petrides and Pandya, 2007; Markov et al., 2012).

In summary, the patterns of BOLD coupling exhibited by the four human medial dorsal frontal clusters exhibited two important features. First, the dissimilarities among the coupling patterns of the four regions suggested important dissimilarities in the networks they were part of. Second, there were important similarities between the coupling patterns of each human cluster and areas in the macaque (SMA, pre-SMA, area 9, and area 10). In the macaque, some of these areas are largely situated on the medial surface (SMA, pre-SMA), but they extend onto the dorsal convexity (area 9) and frontal pole (area 10). Although areas 9 and 10 are associated with social cognitive processes that are especially developed in humans, precursors of such processes may 
exist in other primates and be associated with the same brain regions (Flombaum and Santos, 2005; Sallet et al., 2011; Mars et al., 2012b). Moreover, the BOLD coupling patterns reflected key features of the anatomical connections in monkeys (Petrides and Pandya, 1994, 1999, 2007; Barbas et al., 1999).

\section{Six clusters in the dorsolateral frontal cortex}

The initial tractography-based parcellation identified five areas in the lateral DFC. As in our investigation of medial frontal cortex, we subjected each lateral frontal region to a further parcellation attempt. We were able to parcellate just one lateral frontal area into smaller subdivisions in a consistent manner across subjects; on further analysis, one of the initial clusters was found to be subdivisible into clusters 8 and 9 . We therefore report the features of a total of six clusters found in the lateral frontal cortex (Fig. 9).

Clusters 5 and 6 covered much of the anterior middle frontal gyrus (Fig. $9 a, b$ ). Cluster 5, with a center of gravity at [26, $40,32]$, was more dorsal and slightly more rostral than cluster 6 , with a center of gravity at $[38,25,31]$. While cluster 5 was just ventral to the superior frontal sulcus, cluster 6 was just dorsal to the inferior frontal sulcus. These two clusters spanned most of the region that is typically referred to as dorsolateral prefrontal cortex in discussions of the human brain. It is in this region that working memory-related activations have been reported (Petrides, 2005), and it is this region that is also responsive to a diverse range of tasks often requiring the sequencing of multiple cognitive processes and of behavior that has led Duncan (2010) to describe it as a "multiple demand (MD) system."

Another cluster was found anterior to clusters 5 and 6 (Fig. $9 c$ ) with a center of gravity at $[31,48,11]$. Unlike cluster 5 and 6 , which were squarely placed within the middle frontal gyrus, cluster 7 was largely anterior to the anterior tip of the inferior sulcus, and it surrounded the ascending branch of the intermediate frontal sulcus. Activity in this region is reported in some working memory studies but is less frequently associated with MD tasks (see Fig. 16).

The names given to the cortex assigned to these three clusters have been quite diverse. Activity reported in fMRI studies in the more posterior clusters 5 and 6 is often referred to as being in area 46 , area $9 / 46$, or even in area 9 , while activity in the more anterior cluster 7 is reported as being in the frontal pole, area 10, or sometimes just more simply as being in anterior PFC or rostral PFC. Cluster 7 is in a similar position to the lateral division of area 10 proposed by Gilbert et al. (2006). The present finding of a clear difference in location between cluster 4, described above, and cluster 10 , emphasizes that there is an important difference between these two anterior prefrontal regions. The inter-regional BOLD coupling patterns associated with clusters 5,6 , and 7 , however, suggest that human clusters 5 and 6 may more closely resemble macaque areas $9 / 46 \mathrm{~d}$ and $9 / 46 \mathrm{v}$, while it may be misleading to think of human cluster 7 as being frontal polar but instead that it is more similar to macaque area 46 . The BOLD coupling patterns of the areas are discussed in the next section.

The center of gravity of cluster 8 was at $[30,9,52]$. It was situated in the most posterior part of the middle frontal gyrus, just anterior to the superior precentral sulcus and ventral to the superior frontal sulcus. It therefore occupied a position similar to that proposed for area 8A (Petrides and Pandya, 1999) (Fig. 9d). This region of the human brain is active when the eyes, or the focus of visual attention, move (Amiez et al., 2006; Amiez and Petrides, 2009), and so it has been identified with the frontal eye field (FEF) of the macaque.

Another cluster, cluster 9, lay just dorsal with a center of gravity at $[24,3,55]$. It was situated just dorsal to the superior frontal sulcus and anterior to the precentral sulcus. The area therefore occupied a position that was similar to anterior PMd (Petrides and Pandya, 1999; Picard and Strick, 2001) (Fig. 9e). The area, like PMd in the macaque, is active especially when arm movements, as opposed to eye movements, are made, especially when the rule linking the cue to the action is an arbitrary or learned one (Murray et al., 2000; Passingham et al., 2000; Petrides, 2005; Amiez et al., 2006).

Just anterior to the PMd-like cluster 9, on the lateral part of the superior frontal gyrus, lay another cluster, cluster 10, with a center of gravity at [22, 32, 39] (Fig. 9f). Brodmann (1909) and other anatomists (Von Economo, 1929; Sarkissov et al., 1955) have not distinguished this region of posterior frontal cortex from the region we have referred to as cluster 8 and the FEF. Petrides and Pandya (1999), however, have argued that the re- 


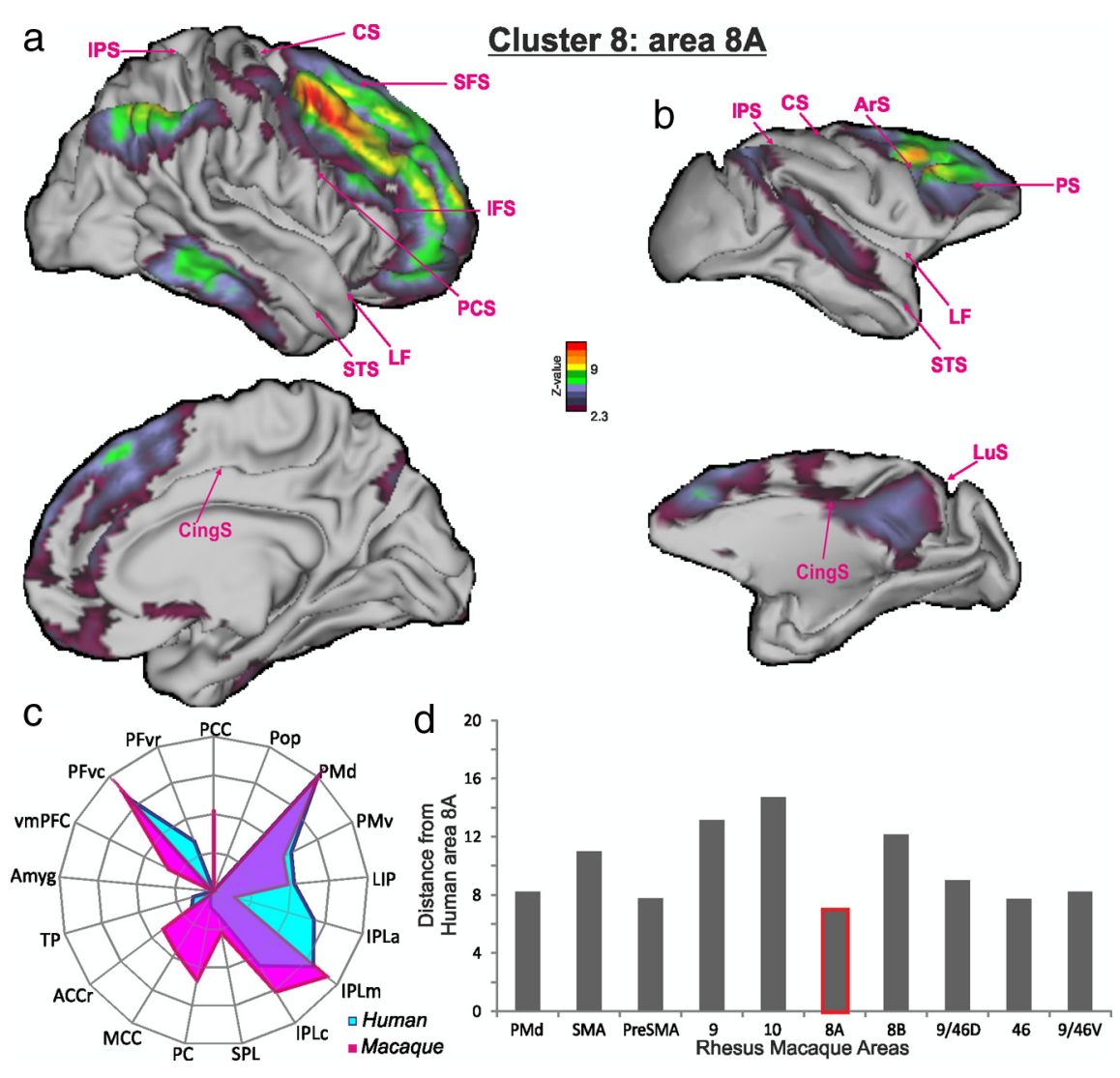

Figure 13. Cluster 8/8A. $\boldsymbol{a}-\boldsymbol{c}$, The BOLD coupling patterns of cluster 8 in human subjects $(\boldsymbol{a})$ and $8 \mathrm{~A}$ in macaques $(\boldsymbol{b})$ and their associated functional connectivity fingerprints in humans and macaques $(\boldsymbol{c})$. $\boldsymbol{d}$, The summed absolute differences between the functional coupling scores suggested that human cluster 8 resembled macaque $8 \mathrm{~A}$ (lowest bar). All other conventions are as in Figure 5.

gion just anterior to PMd and dorsal to the FEF, in other words in the same position as cluster 9, has a distinct cytoarchitecture to the adjacent regions, and they refer to it as area $8 \mathrm{~B}$. Our results support their contention. Because the possibility of a separate brain area within this region has received so little attention and because its location in MNI space has been unknown, there has been little consideration of its specialized function.

\section{Functional coupling of dorsolateral frontal cortex in humans} and macaques

Despite the diversity of descriptions of activity found in cortex corresponding to clusters 5,6 , or 7 , their functional coupling patterns suggested that they have the most in common with macaque areas 9/46d, 9/46v, and 46, respectively. Cluster 5, like 9/46d in the monkey, possessed a BOLD signal that was coupled with IPLm, IPLc, PMd, area 9, and vmPFC (Fig. 10). The BOLD signal of cluster 6 , by contrast, resembled that of macaque $9 / 46 \mathrm{v}$ because it was more strongly coupled with the BOLD signal in PMv and anterior IPL (IPLa), and only weakly with area 9 and vmPFC (Fig. 11). The BOLD coupling patterns resemble the connection patterns established with tracer injection studies in the macaque (Cavada and Goldman-Rakic, 1989; Petrides and Pandya, 1999, 2002, 2009).

Although tissue in the vicinity of cluster 7 is sometimes described as frontopolar or cytoarchitectonic area 10, it was notable that the functional coupling pattern of cluster 7 was very distinct from the known connection patterns of area 10 in the macaque; instead, it resembled the coupling pattern associated with macaque area 46 (Fig. 12). Like cytoarchitectonic area 46 but unlike cytoarchitectonic area 10, the BOLD signal of cluster 7 was coupled with IPLc and IPLm BOLD signals. In the monkey, area 46 has much stronger connections with inferior parietal cortex than cytoarchitectonic area 10 (Petrides and Pandya, 1999, 2007; Rozzi et al., 2006; Markov et al., 2012). Like cytoarchitectonic area 46 but unlike cytoarchitectonic area 10, the BOLD signal of cluster 7 was not coupled with amygdala BOLD signals. In both species, the coupling of area 46/cluster 7 with PC was more prominent than was the case for $9 / 46 \mathrm{~d} /$ cluster 5 and $9 / 46 \mathrm{v} /$ cluster 6 , which is reminiscent of tracer injection studies in the macaque (Cavada and Goldman-Rakic, 1989) and is arguably consistent with a previous report (Margulies et al., 2009). Unlike 9/46v/cluster 6, area 46/cluster 7 lacked strong coupling with PMv in both species, as has been reported in tracer injection studies (Petrides and Pandya, 1999). More posterior parts of macaque area 46, including the region that was the focus of our investigation, were coupled with LIP, but that was no longer the case when we examined more anterior parts of macaque area 46 and human cluster 7. A distinctive feature of macaque area 46 was the strong coupling it exhibited along the length of the STS, while areas 9/46d and 9/46v had less strong coupling that was restricted to anterior STS. Human cluster 7, more so than either cluster 5 or 6 , was coupled with both the posterior and anterior parts of the STS, although such coupling was not evident in the central portion of STS. Whether the mid-section of the human STS is more concerned with auditory and linguistic processes than is the case in the macaque is a current topic of investigation.

The pattern of BOLD coupling seen between the human $8 \mathrm{~A}$-like cluster 8 and the rest of the brain included parts of the parietal cortex such as the intraparietal sulcus region that may correspond to LIP in the macaque (Swisher et al., 2007; Mars et al., 2011) (Fig. 13a). The coupling pattern also extended into IPLc but not IPLa or SPL. It was also notable that there was evidence of coupling between both human cluster 8 and macaque $8 \mathrm{~A}$ and visual association cortex in the lateral occipito-temporal region. In general, the coupling pattern of cluster 8 was similar to that seen for the macaque FEF $8 \mathrm{~A}$ region (Fig. 13b) (Cavada and Goldman-Rakic, 1989; Schall et al., 1995; Petrides and Pandya, 1999; Lewis and Van Essen, 2000). However, in the macaque there was evidence for coupling with the posterior superior temporal gyrus but no such coupling pattern was evident in the human data. Connections between area $8 \mathrm{~A}$ and the superior temporal gyrus in the macaque are most prominent in the dorsal part of $8 \mathrm{~A}, 8 \mathrm{Ad}$ (Petrides and Pandya, 1999).

By contrast, the adjacent rostral PMd-like BOLD signal of cluster 9 was more correlated with SPL as well as dorsal prefrontal cortex (Fig. 14a). A similar pattern was observed for the macaque rostral PMd region, which has been called PMdr or 6DR (Fig. $14 b-d)$. The coupling pattern was reminiscent of this area's con- 
nections (Matelli et al., 1998; Geyer et al., 2000; Luppino et al., 2003).

Although little attention has been given to the distinct functional role of area $8 \mathrm{~B}$, we were able to see that cluster $10 \mathrm{ex}-$ hibited a distinctive coupling pattern that distinguished it from its neighbors (Fig. 15a). Unlike FEF-like cluster 8 or PMdlike cluster 9 , the BOLD signal of 8B-like cluster 10 was coupled with that in vmPFC. Finally, the 8B-like BOLD signal of cluster 10 was not coupled with SPL areas concerned with limb movements as had been the case for the PMd-like cluster 6. A similar pattern, exhibiting the same distinctive features, was also seen in the BOLD coupling pattern associated with $8 \mathrm{~B}$ in the macaque (Fig. 15b-d). These aspects of the coupling pattern of $8 \mathrm{~B} /$ cluster 10 are reminiscent of the connections of $8 \mathrm{~B}$ in tracer injection studies. When we compared the full "connectional fingerprint" of cluster 10 with areas in the macaque using the same distance measure as used above, we found that it was most similar to macaque $8 \mathrm{~B}$.

In a previous study, Goulas et al. (2012) have put forward suggestions for the positions of human DFC areas. The location that they suggest for the region they call "premotor BA6" is similar to the one that we link with cluster 9/PMd. Goulas et al. (2012) identified clusters when they were present and overlapped in just over half (7) of their 12 subjects, whereas the clusters we report were present and overlapped in all 9 of our subjects. With such criteria, it is perhaps not surprising that they identify a greater number of areas. Goulas et al. (2012) refer to three different areas that they name as FEF, $8 \mathrm{Ad}$, and $8 \mathrm{Av}$, which largely fell within our cluster $8 /$ area $8 \mathrm{~A}$. It is therefore possible that further subdivisions exist within cluster 8/area $8 \mathrm{~A}$ but that their positions do not overlap across subjects after registration into MNI space. Goulas et al. (2012) label two different but close and almost interdigitating areas both as $9 / 46 \mathrm{v}$, and each was identified in just over half of their subjects, in the region covered by our cluster 6/area 9/46v. The area we refer to as cluster $7 /$ area 46 lies mostly anterior to the region investigated by Goulas et al. (2012), although it might include some of the region they identify as $45-9 / 46-45$. By contrast, the more posterior region Goulas et al. (2012) refer to as area 46 may be another subdivision of 9/46; it is certainly unlike our cluster 7/area 46 in humans or macaques because it is strongly coupled with ventral premotor cortex.

In summary, within human dorsolateral prefrontal cortex we show similarities between the multiple demand/working memory areas in the central parts of the middle frontal gyrus and areas $9 / 46 \mathrm{~d}$ and 9/46v of the macaque. Even though these regions are often labeled area 46 and likened to area 46 in the macaque, our data suggested that they were less similar to area 46 than they were to $9 / 46 \mathrm{v}$ and $9 / 46 \mathrm{~d}$. The BOLD coupling patterns of the more anterior human dorsolateral tissue adjacent to the frontal pole appeared quite distinct from the frontal pole in the macaque, and instead very similar to macaque 46 . We were also able to identify a human dorsolateral frontal cortical region that has gone virtu- ally unremarked, cluster 10 , which resembled area $8 \mathrm{~B}$ in the macaque.

Finally, we note that Figure 17 illustrates the full crosscorrelation matrix of human and macaque DFC area coupling patterns, while Figure 18 summarizes the DW-MRI-based parcellation scheme we propose for human DFC.

\section{Confirmation of DFC parcellation scheme in an additional group of subjects in left and right hemispheres}

Our DW-MRI tractography-based parcellation analysis was conducted on a similar number of subjects to those in previous studies. Nevertheless, to confirm the generality of the parcellation scheme we also performed a similar DW-MRI tractographybased parcellation analysis on a further group of 25 human subjects, and the results for the left and right hemispheres are presented in Figure 19. It can be seen that the DFC anatomical scheme appeared similar in both hemispheres in the new group of subjects.

\section{Discussion}

It has been known for some time that human DFC consists of subregions, but there has been uncertainty about their nature, location, and relation to brain regions in other primates. An understanding of whether correspondences exist between DFC in humans and other primates is important because the region is associated with cognitive processes that are especially well developed in humans, or even unique to humans, and there have been debates about whether some of the component anatomical subregions might be especially large in, or unique to, humans (Semendeferi et al., 2002; Schoenemann et al., 2005; Saxe, 2006; 


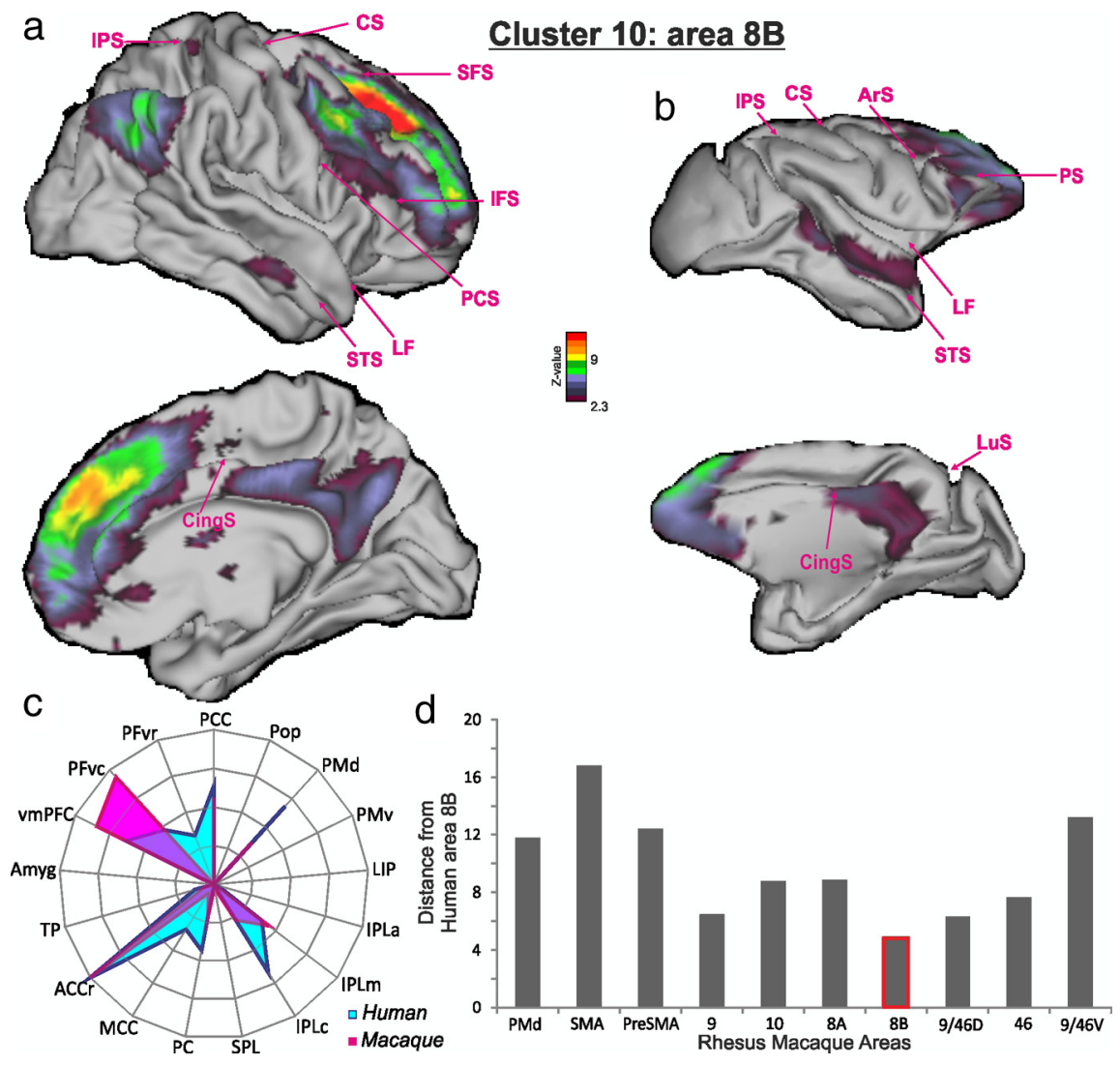

Figure 15. Cluster 10/area 8B. $\boldsymbol{a}-\boldsymbol{c}$, The BOLD coupling patterns of cluster 10 in human subjects $(\boldsymbol{a})$ and area $8 \mathrm{~B}$ in macaques $(\boldsymbol{b})$ and their associated functional connectivity fingerprints in humans and macaques $(\boldsymbol{c})$. $\boldsymbol{d}$, The summed absolute differences between the functional coupling scores suggested that human cluster 10 resembled macaque area $8 \mathrm{~B}$ (lowest bar). All other conventions are as in Figure 5.
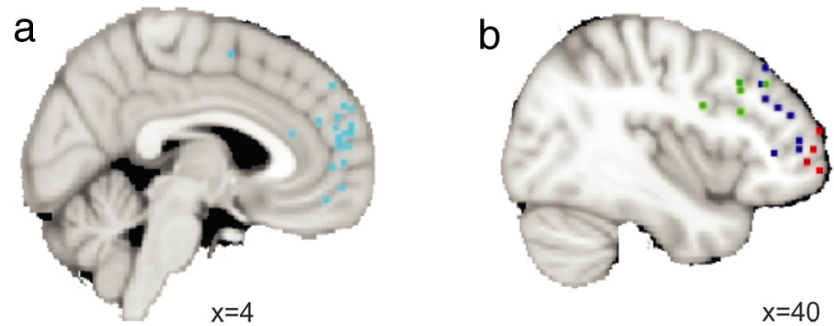

Figure 16. $\quad \boldsymbol{a}$, Activations (light blue dots) associated with theory of mind and the making of inferences about others' beliefs are found in area 10/cluster 4 and area 9/cluster 3 (Amodio and Frith, 2006; Behrens et al., 2008; Van Overwalle and Baetens, 2009). $\boldsymbol{b}$, Activations associated with the monitoring of information in memory (dark blue dots) are found in anterior lateral prefrontal cortex (Sakai et al., 2002; 0wen et al., 2005; Amiez and Petrides, 2007; Champod and Petrides, 2007, 2010). Activity associated with cognitive branching and the representation and monitoring of counterfactual actions (red dots) is situated nearby but a little more ventrally and anteriorly (Daw et al., 2006; Gilbert et al., 2006; Boorman et al., 2009; Amiez et al., 2012). Activity associated with cognitive control demands is associated with more posterior DFC (green dots) (Kerns et al., 2004; Dosenbach et al., 2007; Duncan, 2010).

Burgess, 2011; Koechlin, 2011; Tsujimoto and Genovesio, 2011; Tsujimoto et al., 2011; Passingham and Wise, 2012). In brief, we identified 10 major divisions of human DFC that were consistently located in the same positions in standard MNI space. The BOLD signal in each cluster was coupled in a distinct way with BOLD signals recorded from the rest of the brain. In every case, even when the clusters we identified were in regions associated with social cognitive processes such as theory of mind, we were able to identify regions in the macaque with similar coupling patterns. Moreover, the macaque BOLD signal coupling patterns were reminiscent of the connectional anatomy of the same regions.

Several between-species relationships we report conform with widely held notions. For example, the relationships we report among posterior clusters 1, 2, and 8 , and SMA, pre-SMA, and area $8 \mathrm{~A} / \mathrm{FEF}$ (Johansen-Berg et al., 2004; Amiez et al., 2006; Amiez and Petrides, 2009). There has been greater uncertainty about how areas in more anterior DFC are related.

Clusters 3 and 4 occupied dorsomedial prefrontal cortex. Activity in these clusters has been linked to social cognition when people make social judgments or employ theory of mind to predict the actions, beliefs, and intentions of others (Amodio and Frith, 2006; Lieberman, 2007; Behrens et al., 2008, 2009; Krienen et al., 2010) (Fig. 16). Despite these regions' involvement in social cognition, it also seems that they are active when people reflect on themselves and their own beliefs, intentions, and actions (Amodio and Frith, 2006; Brass and Haggard, 2007; Desmet et al., 2011).

Activity in cluster 3 is apparent not just when subjects are performing theory of mind tasks but also when they are monitoring and predicting their own and others' actions in the absence of inferences about the beliefs and mental states that guide the actions (Ramnani and Miall, 2004; Brass and Haggard, 2007; Desmet et al., 2011; Suzuki et al., 2012). In both species, area 9/cluster 3 was also coupled with premotor areas. Tasks emphasizing mentalizing — reflecting about one's own or another's beliefs - are associated with activity in cluster 4 (Amodio and Frith, 2006; Mitchell, 2009; Tamir and Mitchell, 2010).

Although monkeys may not engage in mentalizing in the manner that humans do, they may possess related skills. They make inferences about what others can see (Flombaum and Santos, 2005) and monitor their actions and their outcomes (Yoshida et al., 2011, 2012; Chang et al., 2013). Moreover, gray matter in areas 9 and 10 increases as the complexity of macaques' social environments increase (Sallet et al., 2011), suggesting areas 9 and 10 may also be important in mediating social cognition in macaques too.

Like area 10 /cluster 4 , cluster 7 was also found in anterior prefrontal cortex, but its position was more lateral (Figs. 9, 18). It has been suggested that this region is a lateral component of the frontal pole and that it has a quite distinct function to a more medial frontal polar area in the vicinity of cluster 4 . The possibility that this region may even be uniquely human has also been raised (Gilbert et al., 2006; Koechlin, 2011; Rushworth et al., 2011; Tsujimoto and Genovesio, 2011; Tsujimoto et al., 2011). Our results bear on several of these controversies. First, they emphasize a profound difference between medial and lateral anterior prefrontal cortex clusters 4 and 7. DW-MRI parcellation identified a consistent boundary between these two regions. Clusters 4 and 7 were also associated with dramatically different patterns of BOLD coupling compared with the rest of the brain. 
We argue, however, that the coupling pattern associated with human cluster 7 suggested that it was different to macaque area 10 and instead similar to macaque area 46 . We emphasize that we follow the definitions of Petrides and Pandya $(1994,1999)$ in using the label 46 to refer to anterior rather than to posterior principle sulcus, which instead they refer to as 9/46d and 9/46v.

In the macaque there are major differences between the connections of areas 10 and 46, and concomitants of each difference were apparent in the regions' BOLD coupling patterns (Figs. 8, 12). While area 46 is connected with IPLc and medial parietal area PC, area 10 has weaker connections with parietal cortex (Cavada and Goldman-Rakic, 1989; Petrides

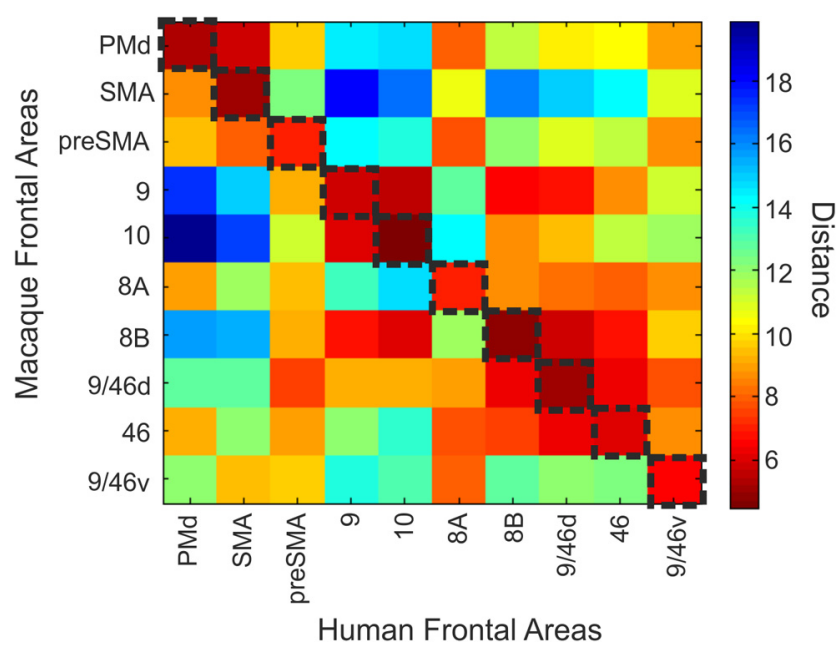

Figure 17. Summary of the full matrix of similarity values between the functional networks associated with human DFC regions (horizontal axis) and macaque DFC regions (vertical axis). Blue colors indicate that there is little difference between the functional networks associated with a macaque and a human DFC area, while red colors indicate greater disparity between areas. Similarity/disparity estimates were based on the summed absolute differences between the functional coupling scores (also shown in panel cof Figs. 5, 6, 7, 8, 10,11, 12, 13, 14, 15). The dashed line indicates the comparison for which the distance value is minimum. and Pandya, 1999, 2007; Markov et al., 2012). Human clusters 7 and 4 resembled macaque cytoarchitectonic areas 10 and 46 respectively; while cluster 7's BOLD signal was coupled with IPLc and PC cluster 4 exhibited no coupling with these areas (Figs. 6, 12). Cytoarchitectonic area 10, by contrast, is more densely interconnected with amygdala than is area 46 (Petrides and Pandya, 1999, 2007) and, again, the BOLD signal of human cluster 4 was more strongly coupled with amygdala BOLD than was the case for cluster 7. A review of fMRI studies and meta-analyses also suggests differences between area 10/ cluster 4 and area 46/cluster 7 of prefrontal cortex (Fig. 16).

Although the suggestion that human cluster 7 resembles macaque area 46 may appear radical, the proposal is in fact consistent with the anatomical scheme advanced by Petrides and Pandya (1999). The only adjustment that might be made to their scheme as it is commonly understood (although not necessarily as it was intended by the authors) is that it should be recognized just how far anterior area 46 is situated. Our study provides an estimate of its location in standard MNI space that can be compared with the results of functional imaging studies.

There were nevertheless differences between the coupling patterns of macaque area 46 and human cluster 7. Macaque area 46 was coupled with the length of the STS, but human cluster 7 was coupled only with rostral and caudal STS. In fact, we were unable to find any human DFC region that coupled with the mid-STS. This probably reflects changes in the tissue that occupies the midSTS in humans and macaques, perhaps as a consequence of expansion of auditory association areas associated with language. We know that there has been major reorganization within the temporal cortex in humans and macaques (Van Essen and Dierker, 2007).

The other areas that we focus on in analyzing BOLD coupling patterns are ones that are more diagnostic (Preuss, 1995) of DFC similarities across species. This is because human-macaque correspondences in these regions themselves are established, and so it is easier to be sure that comparisons are made between like and like when DFC coupling is compared in the two species.
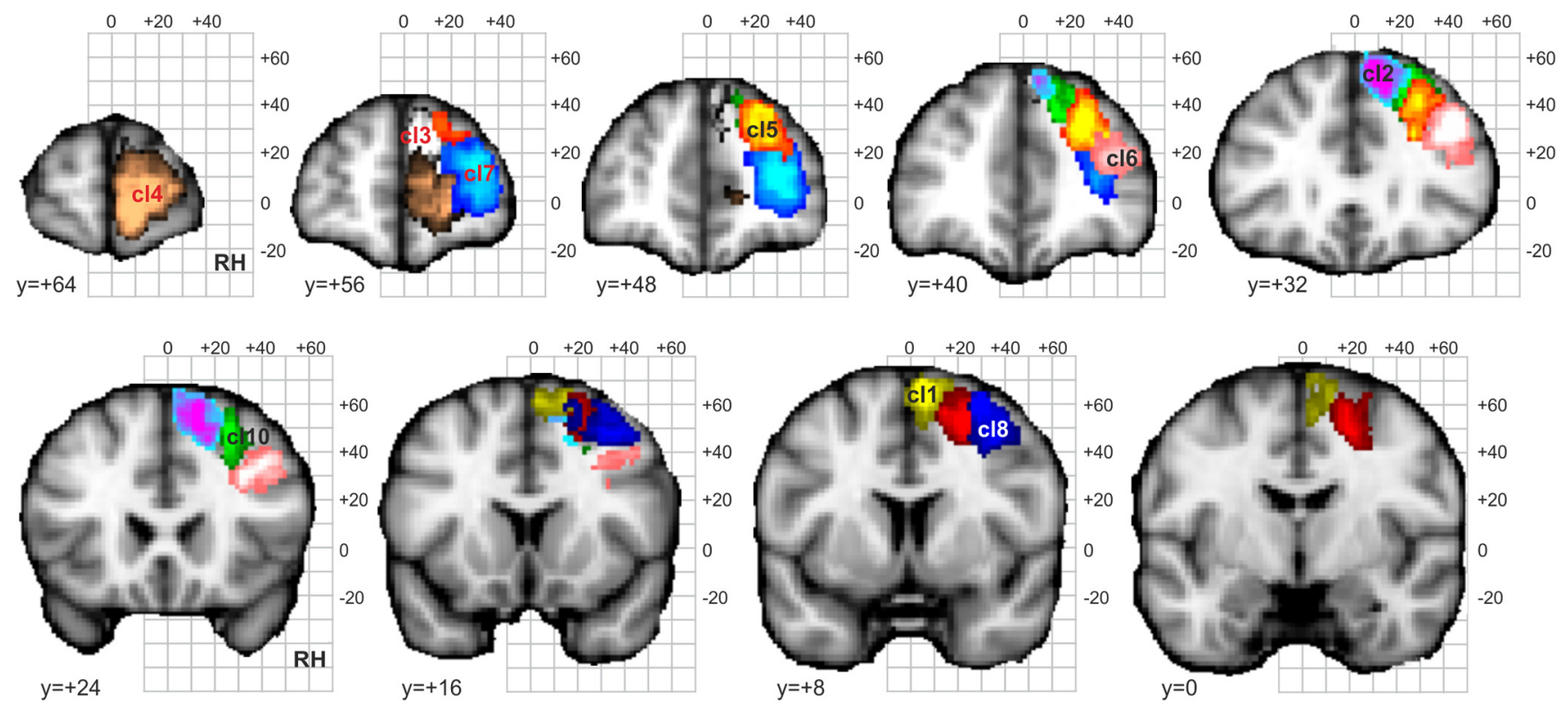

Figure 18. Summary of the DFC parcellation, presented in more detail in Figures 3 and 9 . We refer to cluster 1 as SMA, cluster 2 as pre-SMA, cluster 3 as area 9 , cluster 4 as area 10 , cluster 5 as area 9/46d, cluster 6 as area 9/46v, cluster 7 as area 46 , cluster 8 as area $8 \mathrm{~A}$, cluster 9 as the rostral PMd, and cluster 10 as area $8 B$. The probabilistic tractography was run from vertices at the gray matter/white matter boundary surface. Therefore, for the purpose of this figure, the clusters were dilated (performed using the FSL tool fsImaths) before being transformed (performed using the FSL tool FLIRT) to the MNI space. 


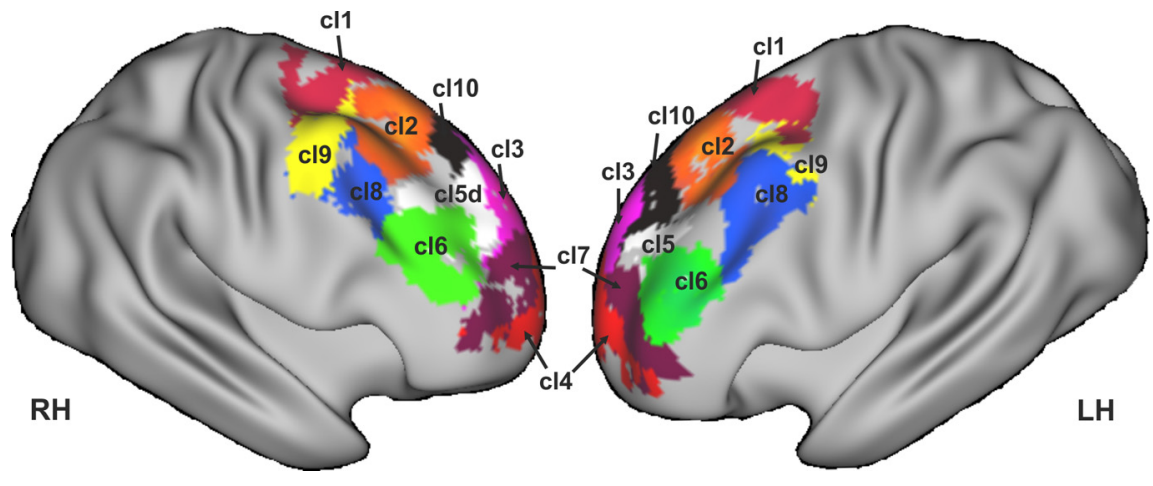

Figure 19. Replication of DFC parcellation in an additional group of 25 subjects in right and left hemisphere. We refer to cluster 1 as SMA, cluster 2 as pre-SMA, cluster 3 as area 9 , cluster 4 as area 10, cluster 5 as area 9/46d, cluster 6 as area 9/46v, cluster 7 as area 46 , cluster 8 as area $8 \mathrm{~A}$, cluster 9 as the rostral PMd, and cluster 10 as area $8 \mathrm{~B}$.

It is possible that there are areas unique to humans in anterior prefrontal cortex outside of the dorsal part that we investigated. One candidate is just ventral and anterior to area $46 /$ cluster 7 (Fig. 16) where activity associated with counterfactual response and prediction errors has been reported (Boorman et al., 2011).

There was also a clear boundary between area $46 /$ cluster 7 and clusters 5 and 6 in the more posterior dorsolateral middle frontal gyrus. Clusters 5 and 6 resembled macaque areas $9 / 46 \mathrm{~d}$ and $9 / 46 \mathrm{v}$ rather than area 46. Unlike human cluster 5 and macaque 9/46d, human cluster 6 and macaque area 9/46v lacked BOLD coupling with superior parietal areas PC and medial intraparietal and with vmPFC. Instead cluster 6 and area 9/46v exhibited more coupling with IPLa, PMv, and PFvr.

Activity related to monitoring and sequencing of information in working memory (Petrides, 1995, 2005; Owen et al., 1998; Amiez and Petrides, 2007), and to monitoring, sequencing, and hierarchical organization of other cognitive operations (Duncan and Owen, 2000; Koechlin et al., 2003; Duncan, 2010) has been reported in clusters 5 and 6 (Fig. 16). Neuronal activity recorded in posterior parts of dorsolateral prefrontal cortex in macaques may reflect similar processes (Sigala et al., 2008; Duncan, 2010).

Finally, we note that our approach does not obviate the need for detailed cytoarchitectonic investigation of DFC and tract tracing studies in animal models. First, it is only such studies that provide us with direct information about brain anatomy rather than an indirect MRI-based estimate of anatomy. Nevertheless, one of the justifications for conducting studies in animal models is that they provide a guide to the understanding of the human brain. We test this assumption here and show that indeed it is the case that key features of human DFC anatomy can be understood in relation to the macaque model.

\section{References}

Aggleton J (2000) The amygdala: a functional analysis, Ed 2. New York: Oxford UP.

Amiez C, Petrides M (2007) Selective involvement of the mid-dorsolateral prefrontal cortex in the coding of the serial order of visual stimuli in working memory. Proc Natl Acad Sci U S A 104:13786-13791. CrossRef Medline

Amiez C, Petrides M (2009) Anatomical organization of the eye fields in the human and non-human primate frontal cortex. Prog Neurobiol 89:220230. CrossRef Medline

Amiez C, Petrides M (2012) Neuroimaging evidence of the anatomofunctional organization of the human cingulate motor areas. Cereb Cortex. Advance online publication. Retrieved May 7, 2013. doi:10.1093/ cercor/bhs329. CrossRef Medline

Amiez C, Kostopoulos P, Champod AS, Petrides M (2006) Local morphol- ogy predicts functional organization of the dorsal premotor region in the human brain. J Neurosci 26:2724-2731. CrossRef Medline Amiez C, Sallet J, Procyk E, Petrides M (2012) Modulation of feedback related activity in the rostral anterior cingulate cortex during trial and error exploration. Neuroimage. Advanced online publication. Retrieved May 7, 2013. doi:10.1016/j.neuroimage.2012.06.023. CrossRef Medline

Amodio DM, Frith CD (2006) Meeting of minds: the medial frontal cortex and social cognition. Nat Rev Neurosci 7:268-277. CrossRef Medline

Anwander A, Tittgemeyer M, von Cramon DY, Friederici AD, Knösche TR (2007) Connectivity-based parcellation of Broca's area. Cereb Cortex 17:816-825. CrossRef Medline

Astafiev SV, Shulman GL, Stanley CM, Snyder AZ, Van Essen DC, Corbetta M (2003) Functional organization of human intraparietal and frontal cortex for attending, looking, and pointing. J Neurosci 23:4689-4699. Medline

Barbas H, Ghashghaei H, Dombrowski SM, Rempel-Clower NL (1999) Medial prefrontal cortices are unified by common connections with superior temporal cortices and distinguished by input from memory related areas in the rhesus monkey. J Comp Neurol 410:343-367. CrossRef Medline

Bates JF, Goldman-Rakic PS (1993) Prefrontal connections of medial motor areas in the rhesus monkey. J Comp Neurol 336:211-228. Medline

Beckmann M, Johansen-Berg H, Rushworth MF (2009) Connectivity-based parcellation of human cingulate cortex and its relation to functional specialization. J Neurosci 29:1175-1190. CrossRef Medline

Behrens TE, Berg HJ, Jbabdi S, Rushworth MF, Woolrich MW (2007) Probabilistic diffusion tractography with multiple fibre orientations: what can we gain? Neuroimage 34:144-155. CrossRef Medline

Behrens TE, Hunt LT, Woolrich MW, Rushworth MF (2008) Associative learning of social value. Nature 456:245-249. CrossRef Medline

Behrens TE, Hunt LT, Rushworth MF (2009) The computation of social behavior. Science 324:1160-1164. CrossRef Medline

Blaizot X, Mansilla F, Insausti AM, Constans JM, Salinas-Alamán A, PróSistiaga P, Mohedano-Moriano A, Insausti R (2010) The human parahippocampal region: I. Temporal pole cytoarchitectonic and MRI correlation. Cereb Cortex 20:2198-2212. CrossRef Medline

Boorman ED, Behrens TE, Woolrich MW, Rushworth MF (2009) How green is the grass on the other side? Frontopolar cortex and the evidence in favor of alternative courses of action. Neuron 62:733-743. CrossRef Medline

Boorman ED, Behrens TE, Rushworth MF (2011) Counterfactual choice and learning in a neural network centered on human lateral frontopolar cortex. PLoS Biol 9:e1001093. CrossRef Medline

Brass M, Haggard P (2007) To do or not to do: the neural signature of self-control. J Neurosci 27:9141-9145. CrossRef Medline

Brodmann K (1909) Vergleichende Lokalisationslehre der Grosshirnrinde in ihren Prinzipien dargestellt auf Grund des Zellenbaues. Reprint (Garey LJ, translator). London: Smith-Gordon, 1994.

Burgess PW (2011) Frontopolar cortex: constraints for theorizing. Trends Cogn Sci 15:242. CrossRef Medline

Caspers S, Geyer S, Schleicher A, Mohlberg H, Amunts K, Zilles K (2006) The human inferior parietal cortex: cytoarchitectonic parcellation and interindividual variability. Neuroimage 33:430-448. CrossRef Medline

Caspers S, Eickhoff SB, Geyer S, Scheperjans F, Mohlberg H, Zilles K, Amunts $\mathrm{K}$ (2008) The human inferior parietal lobule in stereotaxic space. Brain Struct Funct 212:481-495. CrossRef Medline

Caspers S, Eickhoff SB, Rick T, von Kapri A, Kuhlen T, Huang R, Shah NJ, Zilles K (2011) Probabilistic fibre tract analysis of cytoarchitectonically defined human inferior parietal lobule areas reveals similarities to macaques. Neuroimage 58:362-380. CrossRef Medline

Cavada C, Goldman-Rakic PS (1989) Posterior parietal cortex in rhesus monkey: II. Evidence for segregated corticocortical networks linking sensory and limbic areas with the frontal lobe. J Comp Neurol 287: 422-445. CrossRef Medline

Champod AS, Petrides M (2007) Dissociable roles of the posterior parietal 
and the prefrontal cortex in manipulation and monitoring processes. Proc Natl Acad Sci U S A 104:14837-14842. CrossRef Medline

Champod AS, Petrides M (2010) Dissociation within the frontoparietal network in verbal working memory: a parametric functional magnetic resonance imaging study. J Neurosci 30:3849-3856. CrossRef Medline

Chang SW, Gariépy JF, Platt ML (2013) Neuronal reference frames for social decisions in primate frontal cortex. Nat Neurosci 16:243-250. CrossRef Medline

Culham JC, Danckert SL, DeSouza JF, Gati JS, Menon RS, Goodale MA (2003) Visually guided grasping produces fMRI activation in dorsal but not ventral stream brain areas. Exp Brain Res 153:180-189. CrossRef Medline

Daw ND, O'Doherty JP, Dayan P, Seymour B, Dolan RJ (2006) Cortical substrates for exploratory decisions in humans. Nature 441:876-879. CrossRef Medline

Desmet C, Fias W, Hartstra E, Brass M (2011) Errors and conflict at the task level and the response level. J Neurosci 31:1366-1374. CrossRef Medline

Dosenbach NU, Fair DA, Miezin FM, Cohen AL, Wenger KK, Dosenbach RA, Fox MD, Snyder AZ, Vincent JL, Raichle ME, Schlaggar BL, Petersen SE (2007) Distinct brain networks for adaptive and stable task control in humans. Proc Natl Acad Sci U S A 104:11073-11078. CrossRef Medline

Dum RP, Strick PL (2005) Frontal lobe inputs to the digit representations of the motor areas on the lateral surface of the hemisphere. J Neurosci 25: 1375-1386. CrossRef Medline

Duncan J (2010) The multiple-demand (MD) system of the primate brain: mental programs for intelligent behaviour. Trends Cogn Sci 14:172-179. CrossRef Medline

Duncan J, Owen AM (2000) Common regions of the human frontal lobe recruited by diverse cognitive demands. Trends Neurosci 10:475-483. CrossRef Medline

Eickhoff SB, Jbabdi S, Caspers S, Laird AR, Fox PT, Zilles K, Behrens TE (2010) Anatomical and functional connectivity of cytoarchitectonic areas within the human parietal operculum. J Neurosci 30:6409-6421. CrossRef Medline

Filippini N, MacIntosh BJ, Hough MG, Goodwin GM, Frisoni GB, Smith SM, Matthews PM, Beckmann CF, Mackay CE (2009) Distinct patterns of brain activity in young carriers of the APOE-epsilon4 allele. Proc Natl Acad Sci U S A 106:7209-7214. CrossRef Medline

Flombaum JI, Santos LR (2005) Rhesus monkeys attribute perceptions to others. Curr Biol 15:447-452. CrossRef Medline

Frey S, Pandya DN, Chakravarty MM, Bailey L, Petrides M, Collins DL (2011) An MRI based average macaque monkey stereotaxic atlas and space (MNI monkey space). Neuroimage 55:1435-1442. CrossRef Medline

Frith CD, Frith U (2012) Mechanisms of social cognition. Annu Rev Psychol 63:287-313. CrossRef Medline

Geyer S, Matelli M, Luppino G, Zilles K (2000) Functional neuroanatomy of the primate isocortical motor system. Anat Embryol 202:443-474. CrossRef Medline

Ghashghaei HT, Hilgetag CC, Barbas H (2007) Sequence of information processing for emotions based on the anatomic dialogue between prefrontal cortex and amygdala. Neuroimage 34:905-923. CrossRef Medline

Gilbert SJ, Spengler S, Simons JS, Steele JD, Lawrie SM, Frith CD, Burgess PW (2006) Functional specialization within rostral prefrontal cortex (area 10): a meta-analysis. J Cogn Neurosci 18:932-948. CrossRef Medline

Goulas A, Uylings HB, Stiers P (2012) Unravelling the intrinsic functional organization of the human lateral frontal cortex: a parcellation scheme based on resting state FMRI. J Neurosci 32:10238-10252. CrossRef Medline

Grefkes C, Fink GR (2005) The functional organization of the intraparietal sulcus in humans and monkeys. J Anat 207:3-17. CrossRef Medline

Hampton AN, Bossaerts P, O'Doherty JP (2008) Neural correlates of mentalizing-related computations during strategic interactions in humans. Proc Natl Acad Sci U S A 105:6741-6746. CrossRef Medline

Hinkley LB, Krubitzer LA, Padberg J, Disbrow EA (2009) Visual-manual exploration and posterior parietal cortex in humans. J Neurophysiol 102: 3433-3446. CrossRef Medline

Hutchison RM, Gallivan JP, Culham JC, Gati JS, Menon RS, Everling S (2012a) Functional connectivity of the frontal eye fields in humans and macaque monkeys investigated with resting-state fMRI. J Neurophysiol 107:2463-2474. CrossRef Medline

Hutchison RM, Womelsdorf T, Gati JS, Leung LS, Menon RS, Everling S (2012b) Resting-state connectivity identifies distinct functional networks in macaque cingulate cortex. Cereb Cortex 22:1294-1308. CrossRef Medline

Jenkinson M, Bannister P, Brady M, Smith S (2002) Improved optimization for the robust and accurate linear registration and motion correction of brain images. Neuroimage 17:825-841. CrossRef Medline

Johansen-Berg H, Behrens TE, Robson MD, Drobnjak I, Rushworth MF, Brady JM, Smith SM, Higham DJ, Matthews PM (2004) Changes in connectivity profiles define functionally distinct regions in human medial frontal cortex. Proc Natl Acad Sci U S A 101:13335-13340. CrossRef Medline

Kerns JG, Cohen JD, MacDonald AW 3rd, Cho RY, Stenger VA, Carter CS (2004) Anterior cingulate conflict monitoring and adjustments in control. Science 303:1023-1026. CrossRef Medline

Klein JC, Behrens TE, Robson MD, Mackay CE, Higham DJ, Johansen-Berg H (2007) Connectivity-based parcellation of human cortex using diffusion MRI: establishing reproducibility, validity and observer independence in BA 44/45 and SMA/pre-SMA. Neuroimage 34:204-211. CrossRef Medline

Kobayashi Y, Amaral DG (2003) Macaque monkey retrosplenial cortex: II. Cortical afferents. J Comp Neurol 466:48-79. CrossRef Medline

Koechlin E (2011) Frontal pole function: what is specifically human? Trends Cogn Sci 15:241. CrossRef Medline

Koechlin E, Ody C, Kouneiher F (2003) The architecture of cognitive control in the human prefrontal cortex. Science 302:1181-1185. CrossRef Medline

Krause EF (1987) Taxicab geometry. New York: Dover.

Krienen FM, Tu PC, Buckner RL (2010) Clan mentality: evidence that the medial prefrontal cortex responds to close others. J Neurosci 30:1390613915. CrossRef Medline

Lewis JW, Van Essen DC (2000) Corticocortical connections of visual, sensorimotor, and multimodal processing areas in the parietal lobe of the macaque monkey. J Comp Neurol 428:112-137. CrossRef Medline

Lieberman MD (2007) Social cognitive neuroscience: a review of core processes. Annu Rev Psychol 58:259-289. CrossRef Medline

Luppino G, Matelli M, Camarda R, Rizzolatti G (1993) Corticospinal connections of area F3 (SMA-proper) and area F6 (pre-SMA) in the macaque monkey. J Comp Neurol 338:114-140. CrossRef Medline

Luppino G, Rozzi S, Calzavara R, Matelli M (2003) Prefrontal and agranular cingulate projections to the dorsal premotor areas F2 and F7 in the macaque monkey. Eur J Neurosci 17:559-578. CrossRef Medline

Mackey S, Petrides M (2010) Quantitative demonstration of comparable architectonic areas within the ventromedial and lateral orbital frontal cortex in the human and the macaque monkey brains. Eur J Neurosci 32:1940-1950. CrossRef Medline

Margulies DS, Vincent JL, Kelly C, Lohmann G, Uddin LQ, Biswal BB, Villringer A, Castellanos FX, Milham MP, Petrides M (2009) Precuneus shares intrinsic functional architecture in humans and monkeys. Proc Natl Acad Sci U S A 106:20069-20074. CrossRef Medline

Markov NT, Ercsey-Ravasz MM, Ribeiro Gomes AR, Lamy C, Magrou L, Vezoli J, Misery P, Falchier A, Quilodran R, Gariel MA, Sallet J, Gamanut R, Huissoud C, Clavagnier S, Giroud P, Sappey-Marinier D, Barone P, Dehay C, Toroczkai Z, Knoblauch K, Van Essen DC, Kennedy H (2012) A weighted and directed interareal connectivity matrix for macaque cerebral cortex. Cereb Cortex. Advance online publication. Retrieved May 7, 2013. doi:10.1093/cercor/bhs270. CrossRef Medline

Mars RB, Klein MC, Neubert FX, Olivier E, Buch ER, Boorman ED, Rushworth MF (2009) Short-latency influence of medial frontal cortex on primary motor cortex during action selection under conflict. J Neurosci 29:6926-6931. CrossRef Medline

Mars RB, Jbabdi S, Sallet J, O'Reilly JX, Croxson PL, Olivier E, Noonan MP, Bergmann C, Mitchell AS, Baxter MG, Behrens TE, Johansen-Berg H, Tomassini V, Miller KL, Rushworth MF (2011) Diffusion-weighted imaging tractography-based parcellation of the human parietal cortex and comparison with human and macaque resting-state functional connectivity. J Neurosci 31:4087-4100. CrossRef Medline

Mars RB, Sallet J, Schüffelgen U, Jbabdi S, Toni I, Rushworth MF (2012a) Connectivity-based subdivisions of the human right "temporoparietal junction area": evidence for different areas participating in different cortical networks. Cereb Cortex 22:1894-1903. CrossRef Medline

Mars RB, Neubert FX, Noonan MP, Sallet J, Toni I, Rushworth MF (2012b) 
On the relationship between the "default mode network" and the "social brain." Front Hum Neurosci 6:189. CrossRef Medline

Matelli M, Govoni P, Galletti C, Kutz DF, Luppino G (1998) Superior area 6 afferents from the superior parietal lobule in the macaque monkey. J Comp Neurol 402:327-352. CrossRef Medline

Mayka MA, Corcos DM, Leurgans SE, Vaillancourt DE (2006) Threedimensional locations and boundaries of motor and premotor cortices as defined by functional brain imaging: a meta-analysis. Neuroimage 31 : 1453-1474. CrossRef Medline

McGuire PK, Bates JF, Goldman-Rakic PS (1991) Interhemispheric integration: I. Symmetry and convergence of the corticocortical connections of the left and the right principal sulcus (PS) and the left and the right supplementary motor area (SMA) in the rhesus monkey. Cereb Cortex 1:390-407. CrossRef Medline

Mitchell JP (2009) Inferences about mental states. Philos Trans R Soc Lond B Biol Sci 364:1309-1316. CrossRef Medline

Miyachi S, Lu X, Inoue S, Iwasaki T, Koike S, Nambu A, Takada M (2005) Organization of multisynaptic inputs from prefrontal cortex to primary motor cortex as revealed by retrograde transneuronal transport of rabies virus. J Neurosci 25:2547-2556. CrossRef Medline

Morris R, Pandya DN, Petrides M (1999) Fiber system linking the middorsolateral frontal cortex with the retrosplenial/presubicular region in the rhesus monkey. J Comp Neurol 407:183-192. CrossRef Medline

Murray EA, Bussey TJ, Wise SP (2000) Role of prefrontal cortex in a network for arbitrary visuomotor mapping. Exp Brain Res 133:114-129. CrossRef Medline

Neubert FX, Mars RB, Buch ER, Olivier E, Rushworth MF (2010) Cortical and subcortical interactions during action reprogramming and their related white matter pathways. Proc Natl Acad Sci U S A 107: 13240-13245. CrossRef Medline

Owen AM, Stern CE, Look RB, Tracey I, Rosen BR, Petrides M (1998) Functional organization of spatial and nonspatial working memory processing within the human lateral frontal cortex. Proc Natl Acad Sci U S A 95: 7721-7726. CrossRef Medline

Owen AM, McMillan KM, Laird AR, Bullmore E (2005) N-back working memory paradigm: a meta-analysis of normative functional neuroimaging studies. Hum Brain Mapp 25:46-59. CrossRef Medline

Passingham RE (2008) What is special about the human brain? Oxford: Oxford UP.

Passingham RE, Toni I (2001) Contrasting the dorsal and ventral visual systems: guidance of movement versus decision making. Neuroimage 14:S125-131. CrossRef Medline

Passingham RE, Toni I, Schluter N, Rushworth MF (1998) How do visual instructions influence the motor system? Novartis Found Symp 218:129_ 141. Medline

Passingham RE, Wise SP (2012) The neurobiology of the prefrontal cortex anatomy, evolution, and the origin of insight. Oxford: Oxford UP.

Passingham RE, Toni I, Rushworth MF (2000) Specialisation within the prefrontal cortex: the ventral prefrontal cortex and associative learning. Exp Brain Res 133:103-113. CrossRef Medline

Passingham RE, Stephan KE, Kötter R (2002) The anatomical basis of functional localization in the cortex. Nat Rev Neurosci 3:606-616. CrossRef Medline

Petrides M (1995) Impairments of nonspatial self-ordered and externally ordered working memory tasks after lesions of the mid-dorsal part of the lateral frontal cortex in the monkey. J Neurosci 15:359-375. Medline

Petrides M (2000) The role of the mid-dorsolateral prefrontal cortex in working memory. Exp Brain Res 133:44-54. CrossRef Medline

Petrides M (2005) Lateral prefrontal cortex: architectonic and functional organization. Philos Trans R Soc Lond B Biol Sci 360:781-795. CrossRef Medline

Petrides M, Pandya DN (1994) Comparative architectonic analysis of the human and the macaque frontal cortex. In: Handbook of neuropsychology (Boller F, Grafman J, eds), pp 17-58. Amsterdam: Elsevier Science.

Petrides M, Pandya DN (1999) Dorsolateral prefrontal cortex: comparative cytoarchitectonic analysis in the human and the macaque brain and corticocortical connection patterns. Eur J Neurosci 11:1011-1036. CrossRef Medline

Petrides M, Pandya DN (2002) Comparative cytoarchitectonic analysis of the human and the macaque ventrolateral prefrontal cortex and corticocortical connection patterns in the monkey. Eur J Neurosci 16:291-310. CrossRef Medline
Petrides M, Pandya DN (2007) Efferent association pathways from the rostral prefrontal cortex in the macaque monkey. J Neurosci 27:1157311586. CrossRef Medline

Petrides M, Pandya DN (2009) Distinct parietal and temporal pathways to the homologues of Broca's area in the monkey. PLoS Biol 7:e1000170. CrossRef Medline

Picard N, Strick PL (1996) Motor areas of the medial wall: a review of their location and functional activation. Cereb Cortex 6:342-353. CrossRef Medline

Picard N, Strick PL (2001) Imaging the premotor areas. Curr Opin Neurobiol 11:663-672. CrossRef Medline

Preuss TM (1995) Do rats have prefrontal cortex? The Rose-Woolsey-Akert program reconsidered. J Comp Neurol 7:1-24. CrossRef

Ramnani N, Miall RC (2004) A system in the human brain for predicting the actions of others. Nat Neurosci 7:85-90. CrossRef Medline

Ramnani N, Behrens TE, Johansen-Berg H, Richter MC, Pinsk MA, Andersson JL, Rudebeck P, Ciccarelli O, Richter W, Thompson AJ, Gross CG, Robson MD, Kastner S, Matthews PM (2006) The evolution of prefrontal inputs to the cortico-pontine system: diffusion imaging evidence from Macaque monkeys and humans. Cereb Cortex 16:811818. CrossRef Medline

Rozzi S, Calzavara R, Belmalih A, Borra E, Gregoriou GG, Matelli M, Luppino G (2006) Cortical connections of the inferior parietal cortical convexity of the macaque monkey. Cereb Cortex 16:1389-1417. CrossRef Medline

Rushworth MF (2008) Intention, choice, and the medial frontal cortex. Ann N Y Acad Sci 1124:181-207. CrossRef Medline

Rushworth MF, Paus T, Sipila PK (2001) Attention systems and the organization of the human parietal cortex. J Neurosci 21:5262-5271. Medline

Rushworth MF, Noonan MP, Boorman ED, Walton ME, Behrens TE (2011) Frontal cortex and reward-guided learning and decision-making. Neuron 70:1054-1069. CrossRef Medline

Sakai K, Rowe JB, Passingham RE (2002) Active maintenance in prefrontal area 46 creates distractor-resistant memory. Nat Neurosci 5:479-484. CrossRef Medline

Sallet J, Mars RB, Noonan MP, Andersson JL, O’Reilly JX, Jbabdi S, Croxson PL, Jenkinson M, Miller KL, Rushworth MF (2011) Social network size affects neural circuits in macaques. Science 334:697-700. CrossRef Medline

Sarkissov SA, Filimonoff JN, Kononova EP, Preobraschenskaja IS, Kukuew LA (1955) Atlas of the cytoarchitectonics of the human cerebral cortex. Moscow: Medzig.

Saxe R (2006) Uniquely human social cognition. Curr Opin Neurobiol 16: 235-239. CrossRef Medline

Schall JD, Morel A, King DJ, Bullier J (1995) Topography of visual cortex connections with frontal eye field in macaque: convergence and segregation of processing streams. J Neurosci 15:4464-4487. Medline

Scheperjans F, Hermann K, Eickhoff SB, Amunts K, Schleicher A, Zilles K (2008a) Observer-independent cytoarchitectonic mapping of the human superior parietal cortex. Cereb Cortex 18:846-867. CrossRef Medline

Scheperjans F, Eickhoff SB, Hömke L, Mohlberg H, Hermann K, Amunts K, Zilles K (2008b) Probabilistic maps, morphometry, and variability of cytoarchitectonic areas in the human superior parietal cortex. Cereb Cortex 18:2141-2157. CrossRef Medline

Schoenemann PT, Sheehan MJ, Glotzer LD (2005) Prefrontal white matter volume is disproportionately larger in humans than in other primates. Nat Neurosci 8:242-252. CrossRef Medline

Semendeferi K, Lu A, Schenker N, Damasio H (2002) Humans and great apes share a large frontal cortex. Nat Neurosci 5:272-276. CrossRef Medline

Sereno MI, Pitzalis S, Martinez A (2001) Mapping of contralateral space in retinotopic coordinates by a parietal cortical area in humans. Science 294:1350-1354. CrossRef Medline

Sigala N, Kusunoki M, Nimmo-Smith I, Gaffan D, Duncan J (2008) Hierarchical coding for sequential task events in the monkey prefrontal cortex. Proc Natl Acad Sci U S A 105:11969-11974. CrossRef Medline

Smith SM, Jenkinson M, Woolrich MW, Beckmann CF, Behrens TE, Johansen-Berg H, Bannister PR, De Luca M, Drobnjak I, Flitney DE, Niazy RK, Saunders J, Vickers J, Zhang Y, De Stefano N, Brady JM, Matthews PM (2004) Advances in functional and structural MR image analysis and implementation as FSL. Neuroimage 23 [Suppl 1]: S208-S219. CrossRef Medline 
Strick PL, Dum RP, Picard N (1998) Motor areas on the medial wall of the hemisphere. Novartis Found Symp 218:64-75.

Suzuki S, Harasawa N, Ueno K, Gardner JL, Ichinohe N, Haruno M, Cheng K, Nakahara H (2012) Learning to simulate others' decisions. Neuron 74: 1125-1137. CrossRef Medline

Swisher JD, Halko MA, Merabet LB, McMains SA, Somers DC (2007) Visual topography of human intraparietal sulcus. J Neurosci 27:5326-5337. CrossRef Medline

Tamir DI, Mitchell JP (2010) Neural correlates of anchoring-andadjustment during mentalizing. Proc Natl Acad Sci U S A 107:1082710832. CrossRef Medline

Taylor PC, Nobre AC, Rushworth MF (2007) Sub-second changes in topdown control exerted by human medial frontal cortex during conflict and action selection: a combined TMS-EEG study. J Neurosci 27:1134311353. CrossRef Medline

Tomassini V, Jbabdi S, Klein JC, Behrens TE, Pozzilli C, Matthews PM, Rushworth MF, Johansen-Berg H (2007) Diffusion-weighted imaging tractography-based parcellation of the human lateral premotor cortex identifies dorsal and ventral subregions with anatomical and functional specializations. J Neurosci 27:10259-10269. CrossRef Medline

Tsujimoto S, Genovesio A (2011) Appreciating the differences: response to Burgess. Trends Cogn Sci 15:243. CrossRef

Tsujimoto S, Genovesio A, Wise SP (2011) Frontal pole cortex: encoding ends at the end of the endbrain. Trends Cogn Sci 15:169-176. CrossRef Medline

Van Essen DC, Dierker DL (2007) Surface-based and probabilistic atlases of primate cerebral cortex. Neuron 56:209-225. CrossRef Medline

Van Essen DC, Drury HA, Dickson J, Harwell J, Hanlon D, Anderson CH, Drury HA (2001) An integrated software system for surface-based anal- yses of cerebral cortex. J Am Med Inform Assoc 8:443-459. CrossRef Medline

Van OverwalleF, Baetens K (2009) Understanding others' actions and goals by mirror and mentalizing systems: a meta-analysis. Neuroimage 48:564-584. CrossRef Medline

Vincent JL, Patel GH, Fox MD, Snyder AZ, Baker JT, Van Essen DC, Zempel JM, Snyder LH, Corbetta M, Raichle ME (2007) Intrinsic functional architecture in the anaesthetized monkey brain. Nature 447:83-86. CrossRef Medline

Vogt B (2009) Architecture, neurocytology, and comparative organization of monkey and human cingulate cortices. In: Cingulate neurobiology and disease (Vogt B, ed). New York: Oxford UP.

Von Economo C (1929) The cytoarchitectonics of the human cerebral cortex. London: Oxford UP.

Vorobiev V, Govoni P, Rizzolatti G, Matelli M, Luppino G (1998) Parcellation of human mesial area 6: cytoarchitectonic evidence for three seperate areas. Eur J Neurosci 10:2199-2203. CrossRef Medline

Yoshida K, Saito N, Iriki A, Isoda M (2011) Representation of others' action by neurons in monkey medial frontal cortex. Curr Biol 21:249-253. CrossRef Medline

Yoshida K, Saito N, Iriki A, Isoda M (2012) Social error monitoring in macaque frontal cortex. Nat Neurosci 15:1307-1312. CrossRef Medline

Yoshida W, Seymour B, Friston KJ, Dolan RJ (2010) Neural mechanisms of belief inference during cooperative games. J Neurosci 30:10744-10751. CrossRef Medline

Zhang Y, Fan L, Wang J, Zhu M, Yu C, Jiang T (2012) Connectivity-based parcellation of the human posteromedial cortex. Cereb Cortex. Advance online publication. Retrieved May 7, 2013. doi:10.1093/cercor/bhs353. CrossRef Medline 